Portland State University

PDXScholar

$1-1-1976$

\title{
An inter-rater reliability study on the Multi- dimensional outcome measure
}

Grace Boys

Portland State University

Follow this and additional works at: https://pdxscholar.library.pdx.edu/open_access_etds

Part of the Mental and Social Health Commons

Let us know how access to this document benefits you.

\section{Recommended Citation}

Boys, Grace, "An inter-rater reliability study on the Multi-dimensional outcome measure" (1976).

Dissertations and Theses. Paper 567.

https://doi.org/10.15760/etd.567

This Thesis is brought to you for free and open access. It has been accepted for inclusion in Dissertations and Theses by an authorized administrator of PDXScholar. Please contact us if we can make this document more accessible: pdxscholar@pdx.edu. 


\title{
AN INTER-RATER RELIABIIITY STUDY \\ ON THE MULTI-DIMENSIONAL \\ OUTCOME MEASURE
}

\author{
by \\ SISTER GRACE BOYS, S.S.S.
}

A thesis submitted in partial fulfillment of the requirements for the degree of

MASTER OF SOCIAL WORK

Portland State University 1976

(c) Sister Grace Anne Boys 1976 
TO THE OFFICE OF GRADUATE STUDIES AND RESEARCH:

The members of the Committee approve the thesis of

Sister Grace Boys, S.S.S., presented April 27, 1976.

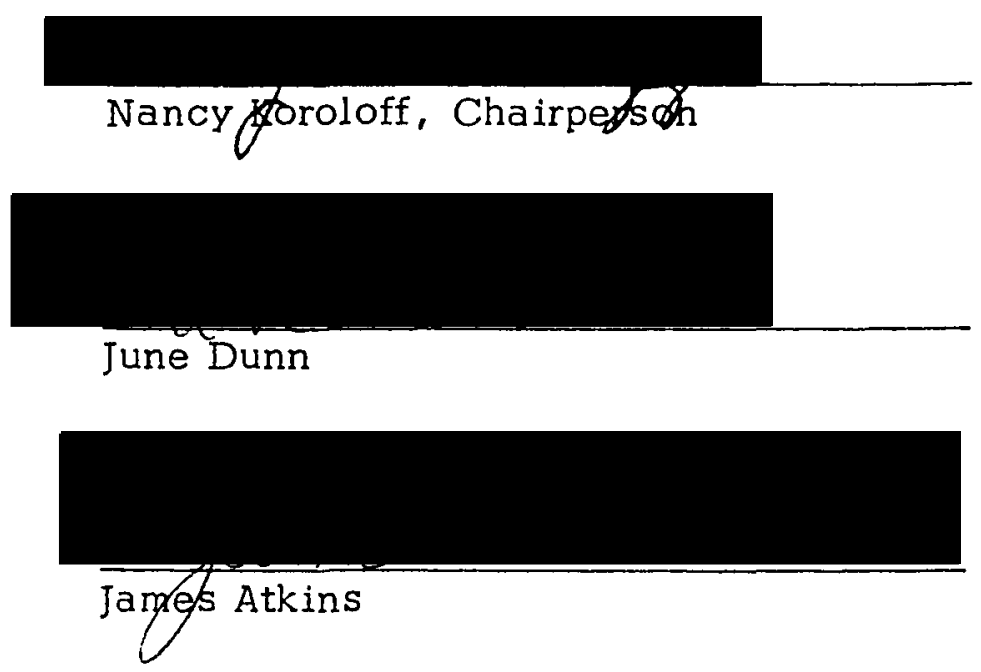

APPROVED:

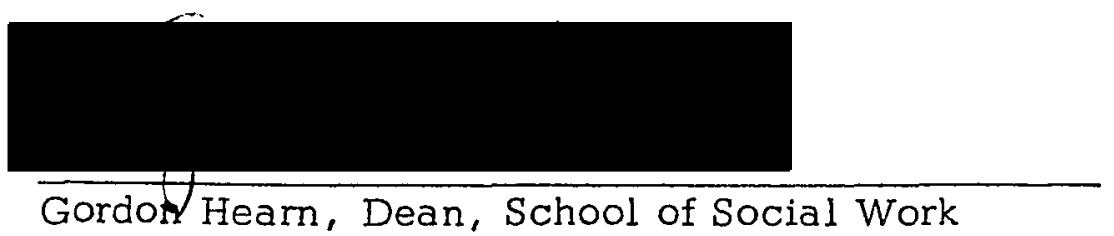

Gordon Hearn, Dean, School of Social Work

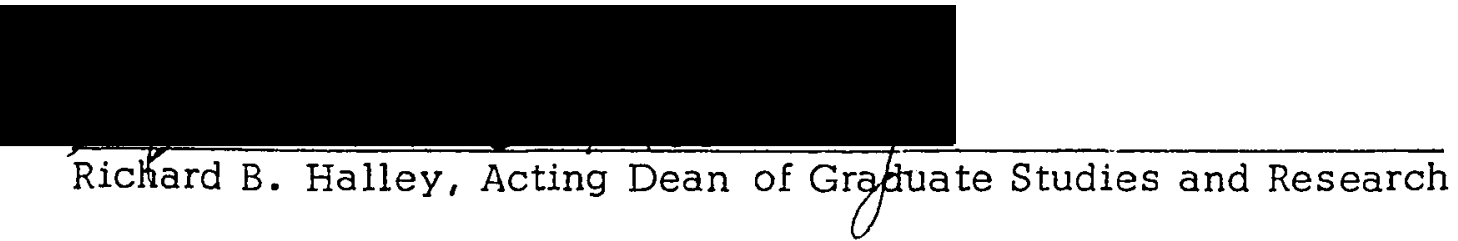

April 27, 1976 
AN ABSTRACT OF THE THESIS OF Sister Grace BOys, S.S.S., for the Master of Social Work presented April 27, 1976.

Title: An Inter-Rater Reliability Study of the MultiDimensional Outcome Measure

APPROVED BY MEMBERS OF THE THESIS COMMITTEE:

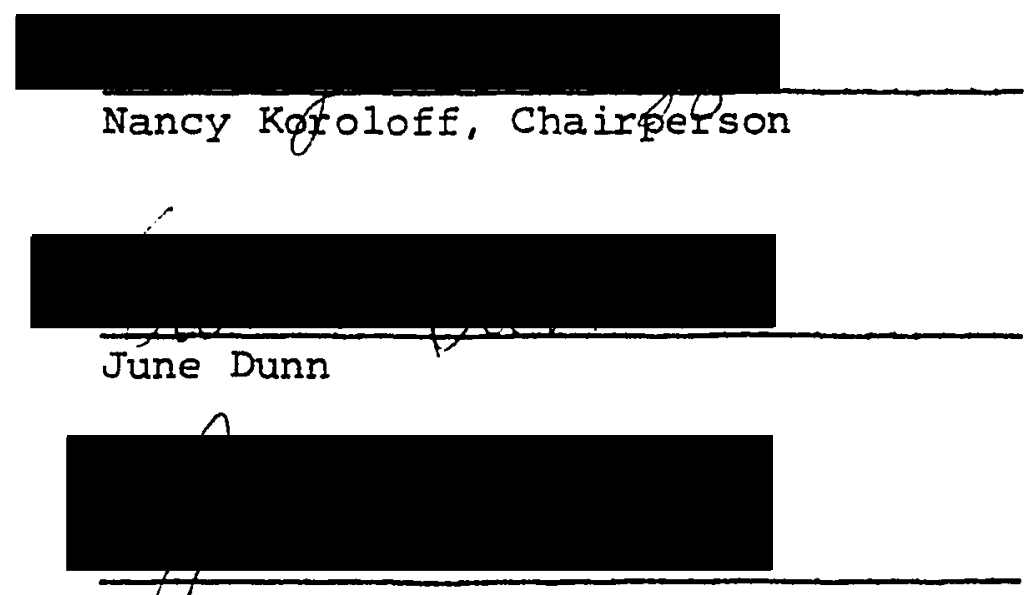

James Atkins

The purpose of the study was to explore the interrater reliability of the Multi-Dimensional Outcome Measure (MDOM) in the following areas: overall reliability, differences in reliability between samples, differences in reliability between scales, and increasing reliability over time. The study was to assist mental health professionals by clarifying the technical properties of an evaluation tool which could be used to document program outcomes for policy makers and to develop more effective treatment methodologies. 
The MDOM was administered to two groups, a mentally and emotionally disturbed sample of thirty-five subjects from an inpatient facility and a normal sample of thirtythree community college subjects. The MDOM was given in back-to-back interviews by two interviewers alternating in first interviewer, second interviewer roles.

The data indicated acceptable inter-rater reliability for the Multi-Dimensional Outcome Measure. For any one sample, all twelve scales showed acceptable reliability according to the criterion of a .75 product moment correlation coefficient. However, four scales did not meet the .75 level: Productivity I (.55), Productivity II (.74), Interpersonal Isolation--Family (.71) when administered to the inpatient sample, and Drug Abuse (.74) when administered to the community college sample.

Assessment of the differences in reliability between samples showed higher reliability for the community college sample than for the inpatient sample with the exception of the Drug Abuse scale. Exploration of the differences in reliability between scales showed some scales contained items which were more relevant for the college student than for the inpatient. Other scales included items which were ambiguous or worded in an awkward manner which may have contributed to their lower reliability. 
Reliability could be increased as a result of the increased skill and clarification of questionable items. Scales which demonstrated unacceptable reliability the first weeks of the study indicated an acceptable level the last week.

The data suggested that interviewers should be trained to insure acceptable reliability. The MDOM was seen to be suitable for monitoring the functioning of a communitybased sample; however, consideration should be given to the inherent limitations before administering the instrument to an inpatient sample. 


\section{To my parents, Mr. and Mrs. E. W. Boys, and friend, Sister Nancy Ann Peck, in gratitude for their personal support and encouragement.}


ACKNOWLEDGEMENTS

This study was made possible by an NIMH training grant in connection with the Community Mental Health Project of Portland State University. The author gratefully acknowledges this financial assistance.

The author wishes to express special appreciation to Elizabeth Brunnette, Ph.D.; James Atkins, Ph.D.; and to Jacqueline Reihman, M.A., who gave of their time and professional expertise in the direction of the study. Gratitude is also given to Randy McPherson who served as co-interviewer and to the staff of the Acute Treatment Unit of the Eastern Oregon Hospital and Training Center without whose assistance data collection would not have been possible.

Special gratitude is given for the continual support, encouragement, and critique of Nancy Koroloff, M.S.W., and June Dunn, M.S.W., who together with James Atkins, Ph.D., served as members of the review panel.

Finally, the author wishes to thank Mary Krumdieck, without whose perseverance and technical assistance this study could not have been completed in its final form. 
TABIE OF CONTENTS

PAGE

ACKNOWLEDGEMENTS • • • • • • • • • • • • • • • •

IIST OF TABIES AND FIGURES . • . . • . • . . . . . vii vi

CHAPTER

I INTRODUCTION . . . . . . . . . . . . . 1

II REVIEW OF THE IITERATURE . . . . . . . . 3

Outcome Measures . . . . . . . 3

Multi-Dimensional Outcome Measure. . . 6

Description of the Measure

Development of the Measure

III DESCRIPTION OF THE PROBLEM . . . . . . . 17

IV METHODOLOGY. • • . • • . . . . . . . 19

Statement of the Research Question. . 19

Selection of Subjects. . . . . . . 20

Acute Treatment Unit Releasees

Blue Mountain Community College

Procedures . . . . . . . . . . 21

$\mathrm{V}$ RESULTS. . . . . . . . . . . . . . 24

Demographics . . . . . . . . . 24

Acute Treatment Unit Releasees

Blue Mountain Community College 
Assessing the Overall Reliability

Exploring Differences of Reliability Between Samples Exploring Differences in Reliability Between Scales Assessing Reliability Over Time Conclusions

VI IMPLICATIONS FOR COMMUNITY MENTAL HEALTH PROGRAM EVALUATIONS. . . . . . . . . 37

Strengths and Weaknesses of the MDOM . 37

Standardization of the Community Norm.

SOURCES CONSULITED. . . . . . . . . . . . . . . . . .

APPENDICES :

APPENDIX A: MULTI-DIMENSIONAL OUTCOME MEASURE

APPENDIX B: SCORING GUIDE, MULTI-DIMENSIONAL OUTCOME MEASURE . . . . . . . 64

APPENDIX $C:$ TABLE VII-MEAN SCORES ON MDOM SCALES, OREGON SELECTED SAMMLES

APPENDIX D: USE OF THE MDOM IN DETERMINING PROGRAM EFFECTIVENESS: A CASE STUDY • • . . . . . . . . 


\section{LIST OF TABLES AND FIGURES}

TABIE

PAGE

I. Admission Type . . . . . . . . . . 25

II. Admitting Diagnoses. . . . . . . . 26

III. Agreement Between Interviewers . . . . 28

IV. Categorical Analysis of Reliability. . . . 32

V. Increasing Reliability Over Time . . . . 34

VI. Mean Scores on MDOM Scales, Oregon

selected Samples....... . . . 73

VII. Paired " $t$ " on Matched Observations . . . 77

FIGURE

1. Average MDOM Standard Scores (Oregon 1975) 43

2. Matched Pairs: Average MDOM Standard Scores (Oregon 1975) . . . . . . . 
CHAPTER I

\section{INTRODUCTION}

While social activists decry the quiescence of the seventies, a silent revolution is occurring at the level of local bureaucracies. Social service agencies in both the public and private sector can no longer content their policy making bodies by stating they are serving the needs. The time has come for documenting program effectiveness. To answer this appeal for increased program accountability, evaluation research has come to the fore.

Mental health professionals may try to side-step the issue of accountability by maintaining that program effectiveness is difficult to measure, but with increasing insistance state and federal legislative bodies are demanding proof that the public dollar is indeed being spent appropriately to ameliorate mental health problems. In addition, recipients of mental health services and their families are beginning to articulate their need for adequate, appropriate and effective treatment intervention.

It is the opinion of this author that program evalua- 
tion will answer this concern for accountability in two ways. First, it will provide the documentation necessary to demonstrate program effectiveness to funding bodies. Second, it will contribute new information that may lead to improved treatment methodologies. At the present time, the state of the art of mental health program evaluation is limited. A major problem faced by program evaluators is the development of an instrument that is both technically sound and reports program outcome in terms easily understood by community decision makers. One of the more promising instruments is the Denver Community Mental Health Questionnaire (DCMHQ). This is a comprehensive community mental health tool developed in the field to assess program outcomes in terms of personal and social functioning. Unfortunately, the utilization of this tool is impeded by the fact that limited information is available on its technical properties. This researcher has elected to explore the reliability of the Denver Community Mental Health Questionnaire. 


\section{CHAPTER II}

\section{REVIEW OF THE LITERATURE}

To provide a conceptual framework for the reliability study, this literature review will present a brief general overview on outcome measures and a more in-depth treatment of the Denver Community Mental Health Questionnaire.

\section{OUTCOME MEASURES}

Outcome measures are relatively new to the evaluation research scene. In the recent work compiled by Hargreaves, McIntyre and associates (1975), eleven general purpose outcome measures are discussed for use with adult mental health clients. Three criteria--emphasis, data source and comprehensiveness--may be utilized to compare these instruments.

First, the emphasis of a measure may be on assessing the symptoms or the actual behavior. The SCI-90: Symptom Checklist (1973), the Psychiatric Status Schedule (1970), and the Brief Psychiatric Rating Scale (1962) emphasize symptomology in their approach. The Katz Adjustment scale 
(1963), the Personal Adjustment and Role Skills Scale (1968), the Psychiatric Status Schedule (1970), and the Denver Community Mental Health Questionnaire (1974) emphasize personal and social functioning.

Second, a measure may be administered using the subject or the clinician as the primary data source. Of the eleven outcome instruments, three--the Katz Adjustment Scale (1963), the Personal Adjustment and Role Skills Scale (1968), and the Denver Community Mental Health Questionnaire (1974)--utilize the subject as the primary data source. The remaining measures utilize the clinician.

Third, a measure may assess one or many dimensions of mental health. The Clinical Global Impression Scale, the Global Assessment Scale (1973), and the Brief Psychiatric Rating Scale (1962) are global measures that report the subject:s overall mental status. The Social Aajustment Scale (1971) and the Denver Community Mental Health Questionnaire (1974) assess many areas of functioning. The Denver Community Mental Health Questionnaire includes two areas not encompassed by most general purpose measures, client satisfaction with the services received and dependency upon public agency resources.

In an unpublished dissertation, Ruth E. Shirley (1975), outlines three possible advantages for the systematic use of 
the DCMHQ in a clinic setting. First, there is a consistent sampling of dimensions assumed to represent mental health. Second, by using the subject as the primary data source, there is a pre-post inter-rater reliability. Third, paraprofessionals can be used to conduct follow-up interviews both within and outside the clinic. The appropriateness of the DCMHQ for use in community mental health programs has also been attested to by the staff of the Manpower Evaluation and Utilization Office of the Oregon Mental Health Division, who state:

The instrument has been shown to be an effective way of measuring the impact of services on clients. It is comprehensive, rather than focusing on one problem area or every conceivable problem area.

The comprehensive behavioral assessment of the Denver Community Mental Health Questionnaire, its usefulness with a variety of community mental health service recipients, the availability of normative data on a community sample, the utilization of service recipients as the primary data source, and the capability to be administered by non-professionals all combine to make this instrument unique among general purpose outcome measures and give it a prominent place for the future in program evaluation. 
MULTI-DIMENSIONAL OUTCOME MEASURE

Description of the Measure

The Multi-Dimensional Outcome Measure (MDOM) is a revision of the Denver Community Mental Health Questionnaire. It is administered during a semi-structured interview and is designed for adults eighteen to sixty-five, regardless of diagnosis. The data are verbal responses to behavior descriptive questions. It may be used effectively with ethnic minorities (particularly Mexican-Americans) and with subjects from differing socio-economic and educational backgrounds. (Ciarlo and Reihman, 1974) The measure addresses twelve dimensions of behavioral functioning. Each of the twelve dimensions was selected because of its relevance to treatment outcome, status as an important concept in community mental health literature, and because of its potential measurability. Each scale is constructed as a fourpoint measure.

Psychological Distress. This scale assesses the subjective sense of distress or discomfort. Sample items include :

Item 30: In the past few days, how often have you felt tense?

Item 31: In the past few days, how often have you had trouble sleeping? 
Interpersonal Isolation--Family. This scale is designed to measure the amount of personal involvement a person has with his family by his own initiative. Typical of this scale are the following items:

Item 17: How much of your free time do you spend with your family?

Item 19: How much would your family be of help and support to you if you found yourself in trouble?

Interpersonal Isolation--Friends. This dimension

measures the degree of involvement a person has with friends or acquaintances. Questions include such items as:

Item 20: How many close friends do you have?

Item 21: How much of your free time do you spend with your friends?

Productivity $I$. This scale assesses a person's engagement in socially valued constructive or self-development activities.

Item 2: Do you work at a job?

Item 5: Do you take any classes, job training, etc., and if so, how much time do you spend per. week?

Productivity II. More recently, experimental items have been developed to assess productivity at home.

Item 6: How much of the housework or cleanup do you do?

Item 7: How much of the care of the children are you responsible for? 
Public Systems Dependency. This scale assesses the respondent's use of public resources to maintain personal functioning.

Alcohol Abuse and Negative Consequences. This scale assesses the consequences experienced as the result of alcohol abuse.

Item 66: When you use alcohol, does it cause any problems with your spouse?

Item 71: When you use alcohol, does it cause any problems with your physical health?

Drug Abuse and Negative Consequences. Similar to the above scale, this assesses consequences of drug abuse. Item 81: When you use drugs, does it cause any problems with your self?

Frequency of Hard Drug Use. This is a single item which measures to what extent a person uses illegal narcotics.

Item 87: How often have you used Heroin, Opium, or Morphine?

Frequency of Soft Drug Use. This measures the degree of abuse of soft drugs, including "street drugs" and prescribed drugs.

Item 85: How often have you used Barbiturates (sedatives, sleeping pills, "downers")? Was all of it prescribed, some of it, or none of it prescribed?

Client Satisfaction. This scale is designed to 
measure what effects the program has on a person's attitudes and feelings. Items include:

Item 91: When you came to the hospital/clinic, did the admission person make you feel comfortable?

Item 94: Do you feel differently about your problem(s) now?

Interpersonal Aggression--Friends. This scale

measures the frequency of verbally and physically assaultive behavior with friends. It is limited in usefulness because of its low reliability. (Ciarlo and Reihman, 1974)

Item 24: When you are with your friends, how often do you arque with them?

Legal Difficulties. This final dimension assesses the occurrences of behaviors involving arrests and court actions. This scale is also limited in its usefulness because of poor reliability. (Ciarlo and Reihman, 1974)

Item 60: How many times in the past year have you been arrested on intoxication-related charges?

Development of the Measure

Guiding Considerations. The MDOM was developed by Ciarlo and Reihman of the Mental Health Systems Evaluation Project of the Northwest Denver Mental Health Center and the University of Denver during field conditions in a mental health clinic within the constraints of agency funding. 
Guiding the development of the measure were seven basic considerations for the construction of outcome measures. (Ciarlo et al., 1972) (1) The measure should address major problems about which the community is concerned, the community being the decision-making and funding bodies affecting mental health policy. (2) It should be applicable for all types of community mental health program clientele, with a variety of diagnoses or problem areas. (3) The instrument should address itself to what program managers and clinicians feel they want to accomplish. (4) The measure should be unrelated to specific treatment programs or individual intervention. (5) The instrument should be assessable by sensitive, well trained, but not necessarily professionally skilled persons. (6) The outcome measure procedures should work well with a wide variety of clients of differing socioeconomic and educational backgrounds as well as differing treatment careers. (7) The instrument should be appropriate to the evaluation methodology being employed.

Validity. In the development of any measuring instrument, there are two important methodological criteria to be considered, validity and reliability. Validity refers to the degree to which any measure or procedure succeeds in doing what it cims to do. This criterion reflects systematic or constant errors in some form of bias which influences 
the result of an evaluation study in a particular direction rather than at random. The entire process of evaluation, from the formulation of objectives through the collection and interpretation of data, is involved in validity questions. To distinguish among the types of validity criteria, Suchman (1967) enumerates the following:

1. Face Validity. This is the obvious significance of the measure as judged by the evaluator.

2. Consensual Validity. This is a type of face validity which utilizes a panel of experts for judgment.

3. Correlational or Criterion Validity. One correlates a measure with something else which is known to measure the variable under consideration.

4. Predictive Validity. One correlates the present measure with something happening in the future.

Face and criterion validity were evaluated in the development of the MDOM. The evaluation project staff assumed face validity on the self-report of service recipients that particular items included in the measure were important in the maintaining of their personal and social functioning. Correlational or criterion validity was assessed in three studies: review of client records, testing for systematic decline in scores of treatment subgroups, and establishing normative data on a community sample.

In the review of client records study, clinicians who had contact with particular clients or their records were 
asked to complete an eleven-item rating scale. Each item's content closely approximated the description of each MDOM scale. Project staff then compared the rating scales with the MDOM scores $(n=71)$. Although there was low agreement between the clinician ratings and the MDOM scores, all correlations were positive with the exception of the Soft Drug Use. (Ciarlo and Reihman, 1974) A further review of client records was conducted by the inpatient services chief of the mental health center. He reviewed records of discharged clients who were assessed to have "good" and "poor" treatment outcomes. Selecting five from each category, staff then compared the MDOM follow-up scores and calculated the mean for each group. With the exception of Public Systems Dependency, all scales differed in favor of the "good" outcome group. (Ciarlo and Reihman, 1974)

The second validity criterion which was tested by project staff involved four client subgroups. By utilizing scores for inpatients, day care, outpatients, and discharged outpatients, a rough index of poor functioning was developed. Evaluation staff tested for a systematic decline in scores across all four groups. All scale differences were in the expected direction; however, only two of the six scales tested, Productivity and Substance Abuse, showed significant difference (a one-tailed " $t$ " test) at the .001 level. 
(Ciarlo et al.. 1972)

The final validity criterion established a normative data base from a Denver community sample. A stratified random sample of community respondents were given the questionnaire, with the exception of the Frequency of Hard and Soft Drug Use items and the Client Satisfaction scale. The community group scores $(n=90)$ were higher (more favorable) than a combined sample of clients $(n=538)$. The difference in mean scores was significant at the .001 level on all scales excepting the Interpersonal Aggression--Friends. Reliability. Validity and reliability are interdependent; without reliability there can be no validity. The reliability of any measuring instrument consists in determining how much of the variation in scores among individuals is due to inconsistencies in the measurement. Reliability reflects the degree to whicn an instrument can demonstrate consistent results upon repeated application. In his analysis of reliability, Suchman (1967) lists five sources of inconsistencies.

1. Subject Reliability. The Subject's mood, motivation, and fatigue may affect his physical and mental health and may produce changes in his responses.

2. Observer Reliability. Similar personal factors may affect the judgments of the observer or rater of the measure. They may also tend to affect the response of the Subject. 
3. Situational Reliability. The conditions under which the instrument is administered may affect the results.

4. Instrument Reliability. Certain aspects of the instrument itself, such as poorly worded questions, may affect the measurement.

5. Processing Reliability. Scoring or coding procedural errors may lead to a lack of reliability.

Developers of the MDOM were concerned with subject reliability--do subjects tend to answer the questions truthfully or do they tend to distort their answers; and observer reliability--can different interviewers obtain high agreement when independently scoring the same interview. To substantiate the reliability of the subjects' responses, researchers compared the clients' responses with similar scores from interviewers and collaterals who could make independent, objective judgments about the client. With the exception of the Interpersonal Aggression--Friends and Legal Difficulties scales, all correlations between the subject and rater $(n=349)$ were above .90 . Although correlations were lower (.59 to .87 ) between the Subject and collaterals $(n=91)$ and rater and collaterals (.53 to .73 with a $n=91)$, all were in the positive direction. This agreement level is high enough to allow client responses to be scored as the primary outcome measure, since information gathered by the interviewer, as reflected in independent judgments, does not 
measurably differ from the client outcome scores. (Ciarlo and Reihman, 1974)

To test the inter-rater reliability, pairs of interviewers were asked to sit in together on a series of eighteen interviews and to independently score the client's responses. The subjects were service recipients of the community mental health facility in Denver. All resultant product moment correlations were .85 or above for all twelve scales. Figures for Frequency of Hard and Soft Drug Use were not included in this study, since these scales were not routinely administered at the time the pair of client scores were obtained. (Ciarlo and Reihman, 1974)

Of the twelve dimensions studied, Interpersonal Aggression--Friends and Legal Difficulties showed marginal reliability and were judged to have limited usefulness by Ciarlo and Reihman (1974).

As reviewed above, the Multi-Dimensional Outcome Measure has demonstrated favorable qualities as an outcome measure. It has the comprehensiveness, treatment sensitivity, and practicality which are appropriate for systematic monitoring of community mental health programs. Validity and reliability measures are marginal, but adequate. It would appear to this author that the greatest strength of the MDOM is also its greatest weakness. It was developed in 
the field setting of a community mental health agency, which increases its applicability for community mental health programs. However, the constraints of this same agency setting preclude a more complete evaluation of the validity and reliability criteria. 
CHAPTER III

DESCRIPTION OF THE PROBLEM

Reliability is a crucial area in the utilization of an outcome measure. One must be able to ascertain that different scores on a single subject are true differences rather than inconsistencies in the instrument or the interviewing procedure. This is especially important in communit; ilental health settings where the same client may be enrolled in multiple programs and assessed by different observers.

It has already been demonstrated that subjects can be used as primary data sources with the assurance that they do not distort their responses. For this purpose, Denver Evaluation Project staff assessed several hundred respondents. However, only eighteen interviews, attended by an interviewer and a second observer/rater, were studied to substantiate inter-rater reliability. (Ciarlo and Reihman, 1974) It would appear that the developers of the Multi-Dimensional Outcome Measure were disproportionately concerned with Subject reliability. What remains to be explored is the 
research question that independent interviewers can administer the MDOM with acceptable reliability. It is the purpose of this research to substantiate the inter-rater reliability of the MDOM utilizing a back-to-back interview technique. 
CHAPTER IV

METHODOLOGY

Given the task of establishing inter-rater reliability of a particular instrument, it is necessary to review three research contingencies. First, the research question must be clearly and succincily stated in measurable terms. Second, one must consider the selection of sample subjects and the influence of the particular settings. Third, the specific procedures to be utilized in the study must be adequately documented to insure the possibility of duplicating the study.

STATEMENT OF THE RESEARCH QUESTION

In this study, the primary focal point is to establish the overall inter-rater reliability of the Multi-Dimensional Outcome Measure. To more comprehensively view the research question, four critical areas of reliability will be examined:

1. Assessing the overall reliability of the instrument. 
2. Exploring differences in reliability between the selected samples.

3. Exploring differences in reliability between the different scales of the instrument.

4. Assessing reliability over time as the interviewers gain skili and competence with the instrument.

A working criterion of a .75 product moment correlation will be utilized as a measure of acceptable reliability for the instrument on any particular scale.

\section{SELECTION OF SUBJECTS}

Two distinct samples have been selected for this study: one, a mentally/emotionally disturbed group of pending releasees of the Acute Treatment Unit of the Eastern Oregon Hospital and Training Center, and two, a normal group of undergraduate psychology and sociology majors enrolled in a community college.

\section{Acute Treatment Unit Releasees}

The Acute Treatment Unit of the Eastern Oregon Hospital and Training Center is a short-term treatment facility for persons with mental and emotional disturbances and alcohol and drug use and abuse problems. This unit, located in Pendleton, Oregon, serves the thirteen counties and two Indian reservations of Eastern Oregon. The four wards which 
comprise the unit are characterized by a patient government, personalism, and a helping milieu directed by an interdisciplinary staff. Patients are assigned to treatment teams according to the county from which they have been admitted. Those patients who were within seven days of release were selected as Subjects and were referred for interviewing by unit social workers. A researcher then arranged with the Subjects for a voluntary participation in two interviews. Thirty-five releasees were interviewed during a six-week period, from October to December, 1975.

\section{Blue Mountain Community College}

The community college, also located in Pendleton, Oregon, draws its students from the surrounding rural Umatilla, Wheeler, Gilliam, and Morrow counties. Two undergraduate classes were selected as sample subjects. Subjects were requested to volunteer for the study after a project description was presented to each class. Thirty-three out of approximately fifty students were interviewed during a three-week period, November to December, 1975.

\section{PROCEDURES}

Previous inter-rater reliability checks on the MDOM used a single interview observed by two raters to establish 
reliability. This procedure produces a single response, to a single interviewer, in a setting identical for both raters. The subject, the interviewer, the environment, and the instrument are all eliminated as possible sources of variance, a condition quite unlike field conditions where the instrument will be utilized. It is the purpose of this study to ascertain the reliability of the instrument using independent interviews with the same subject.

A back-to-back interview design was employed in which one interviewer immediately followed the second while alternating first-interviewer, second-interviewer roles with subsequent subjects. Introductory remarks to each subject were semi-structured to more closely simulate field conditions, and the establishment of personal rapport and further clarification of scale items were dependent upon the particular style of each interviewer.

At the beginning of each interview set, the initial interviewer explained the role of the interviewer and the sponsoring agency, the content and purpose of the questionnaire, the voluntary nature of his/her participation, the necessity for cooperation, and the confidentiality of the questionnaire. The Subject was then given the opportunity to ask questions about the instrument and/or to decline to participate. The interviewer then either proceeded with the 
questionnaire or terminated the interview. The inpatient Subjects received three dollars for their participation at the close of the second interview. Only those subjects who were hesitant to participate were informed of the remuneration prior to administering the MDOM.

The interviewers for this study were one undergraduate psychology student and the author. During the three-month study period, the author was engaged in a block field placement with the Eastern Oregon Comprehensive Community Mental Health Center. The Center provides and coordinates all mental health service delivery throughout the catchment area of Eastern Oregon. An integral part of service delivery, research and evaluation, is also provided for affiliate agencies under the supervision of the Community Mental Health Specialist, James Atkins. The interviewers were prepared in the administration of the MDOM by Jacqueline Reihman, one of the principal developers of the measure. This training included operationalizing definitions for each item, practice intervisws, and clarification of all ensuing ambiguities. The interviewers were encouraged to conduct the interviews in the objective manner of research rather than therapeutic intervention. During the data collection period, further clarifications of the instrument were obtained by utilizing Ms. Reihman as the principal consultant. 


\section{CHAPTER V}

\section{RESULTS}

In analyzing the data, it is necessary to present two types: the demographic description of the selected samples and the statistical findings in relation to the question of reliability.

\section{DEMOGRAPHICS}

Hargreaves et al. (1975) give three essential reasons for the inclusion of demographic descriptions: (1) it enables the comparison of several studies to determine if they are similar populations; (2) it allows for a check on the random assignment or assists in matching subjects when randomization is not attempted; and (3) it provides a basis for identifying subgroups that may differ in success among the various treatments being compared.

\section{Acute Treatment Unit Releasees}

Thirty-five inpatient interviews were completed, eight refused, and one respondent was unable to complete the interview. Twenty-nine interviewees were male. Three-fourths of 
the respondents were separated/divorced ( 45.7 percent) or married ( 31.4 percent). The least frequently reported marital status was that of a single person. The age distribution for the inpatient sample had a range between 18 and 67 , with a median of 45, a mean of 44.3 , and a mode of 53 years. Admission type is presented in Table I. Over two-thirds ( 68.5 percent) of all respondents were voluntary admissions to the hospital; 14.2 percent were involuntary court commitments.

TABIE I

ADMISS ION TYPE

\begin{tabular}{|l|c|c|}
\hline \multirow{2}{*}{ Category } & \multicolumn{2}{|c|}{$\begin{array}{c}\text { Acute Treatment Unit } \\
\text { Releasees }\end{array}$} \\
\hline Voluntary & $n$ & $\%$ \\
\cline { 2 - 3 } Court & 24 & 68.5 \\
Emergency Care & 5 & 14.3 \\
Return Trial Visit & 1 & 2.9 \\
Court Hold & 1 & 5.8 \\
Detention Warrant & 2 & 2.9 \\
\hline \hline
\end{tabular}

The admitting diagnoses for the sample presented in 
Table II are from Subjects' hospital records. The most frequent categories are Alcoholism (42.8 percent) and Schizophrenia ( 37.1 percent). The next most frequent category is also alcohol-related, with Alcohol Psychosis at 8.6 percent.

TABIE II

ADMITTING DIAGNOSES

\begin{tabular}{|l|c|c|}
\hline \multirow{2}{*}{ Category } & \multicolumn{2}{|c|}{$\begin{array}{c}\text { Acute Treatment Unit } \\
\text { Releasees }\end{array}$} \\
\hline Alcohol Psychosis & $\mathrm{n}$ & $\%$ \\
\cline { 2 - 3 } Schizophrenia & 3 & 8.6 \\
Neuroses & 13 & 37.1 \\
Personality Disorder & 1 & 2.9 \\
Alcoholism & 15 & 2.9 \\
Adjustment Reaction & 1 & 42.8 \\
Non-Psychotic Organic & 1 & 2.9 \\
Brain Symdrome & 1 & 2.9 \\
\hline \hline Totals & 35 & 100.1 \\
\hline
\end{tabular}

The data for admission type and admitting diagnoses, Tables I and II, were gathered after the administration of the instrument. This was to insure that the interview situation would not be contaminated by a prior knowledge of any respondent. 
Blue Mounta in Community College

Data was compiled for thirty-three community college students, eleven males and twenty-two females, with one refusal and one interview lost in the scoring procedure. Two-thirds of the students were single, 18.2 percent were married, 12.1 percent were divorced or separated, and one student indicated an "other" category. Age data produced a range of 17 to 47 years, a median age of 23.7, a mean age of 20, and a mode of 19 years.

\section{RELIABILITY FINDINGS}

To substantiate the inter-rater reliability of the Multi-Dimensional Outcome Measure, this researcher will present and discuss the data relative to the critical areas of the research question:

1. Assessing the overall reliability of the instrument.

2. Exploring differences in reliability between the selected samples.

3. Exploring differences in reliability between the different scales of the instrument.

4. Assessing reliability over time as the interviewers gain skill and competence.

Assessing the Overall Reliability

In the original development of the Multi-Dimensional 
Outcome Measure, reliability was established in two areas, agreement between the interviewer and the reliability of the Subject's answers themselves. Table III compares the agreement between interviewers in the Denver sample and the two Oregon samples.

\section{TABIE III}

\section{AGREEMENT BETWEEN INTERVIEWERS}

\begin{tabular}{|c|c|c|c|}
\hline \multirow[b]{2}{*}{ Scale Name } & \multirow[b]{2}{*}{$\begin{array}{l}\text { Denver } \\
\text { Sample } \\
\text { ( } \mathrm{n}=18)\end{array}$} & \multicolumn{2}{|c|}{ Oregon } \\
\hline & & $\begin{array}{c}\text { ATU } \\
\text { Releasees } \\
(n=35)\end{array}$ & $\begin{array}{c}\text { BMCC } \\
\text { Students } \\
(n=33)\end{array}$ \\
\hline Productivity I & .88 & .55 & .91 \\
\hline $\begin{array}{l}\text { Interpersonal Isolation-- } \\
\text { Family }\end{array}$ & .93 & .71 & .86 \\
\hline $\begin{array}{l}\text { Interpersonal Isolation-- } \\
\text { Friends }\end{array}$ & .94 & .88 & .96 \\
\hline $\begin{array}{l}\text { Interpersonal Aggression-- } \\
\text { Friends }\end{array}$ & 1.00 & .82 & .87 \\
\hline Psychological Distress & .98 & .92 & .96 \\
\hline Public Systems Dependency & .85 & .91 & .99 \\
\hline Legal Difficulties & 1.00 & .90 & .97 \\
\hline $\begin{array}{l}\text { Alcohol Abuse and } \\
\text { Negative Consequences }\end{array}$ & .87 & .95 & .99 \\
\hline $\begin{array}{l}\text { Drug Abuse and } \\
\text { Negative Consequences }\end{array}$ & .92 & .87 & .74 \\
\hline Soft Drug Use & $\mathrm{n} / \mathrm{a}$ & .81 & .97 \\
\hline Client Satisfaction & .99 & .97 & $\mathrm{n} / \mathrm{a}$ \\
\hline Productivity II & $\mathrm{n} / \mathrm{a}$ & .74 & .95 \\
\hline
\end{tabular}


The principal intent of the instrument is to provide a measure for program effectiveness in community mental health programs, and not for institutionalized Subjects. However, the high reliability of the inpatient data suggests that the instrument has potential for use in many treatment settings.

\section{Exploring Differences of Reliability Between Samples}

The data obtained from the student sample show higher reliability than the inpatient data with the exception of the Drug Abuse Scale. Three scales--Productivity I, Interpersonal Isolation-Family, and Productivity II--show unacceptable reliability (below .75) for the inpatient sample and acceptable reliability for the student sample. This is especially apparent in Productivity I (.55 vs. .91). This difference appears to have been the result of an interviewer definition discrepancy on Item 4 pertaining to volunteer work.

The differences in reliability between student and inpatient shown in Interpersonal Isolation--Family and Productivity II appear to result from the easier application of some items to the student sample. Interpersonal Isolation-Family measures the isolation from the primary family, a term with which the students can more readily identify. The college student is recently separated from his or her parents 
and readily identifies a parents-children living unit as a family. In contrast, the inpatient is older and is more likely to live in circumstances where a primary family is less obvious, e.g., with a brother or sister, a friend, or in a boarding house. Because of the construction of this four-item scale, if the subject states they have no primary family, then two items are excluded. This results in a twoitem scale that has a greater probability of showing unreliability.

The Productivity II scale has many experimental items measuring household duties linked together in an attempt to measure in-home productivity. To apply this scale to the inpatient sample, it was necessary to operationalize the questions in relation to hospital duties. For example, Item 6: "How much of the clean-up of your living quarters do you do?" often elicited respondent requests for clarification that were left to the judgment of the interviewer. These scale items were much more readily applicable to the community college sample and required less clarification. The items included in Productivity II are still being tested for use and are not an integral part of the measure. However, this scale has possibilities for increased utility with further refinement. 
Exploring Differences in Reliability Between Scales

of the twelve scales tested for agreement between interviewers, four feli short of the working criteria of .75 ; Productivity I, especially, showed low reliability with a .55 correlation. Interpersonal Isolation--Family, Drug Abuse, and Productivity II tested in the .70 to .74 range.

For all three samples, eight of the scales exhibit an acceptable level of agreement between interviewers. Three scales: Drug Abuse, Productivity II, and Interpersonal Isolation--Family, show low correlation for any one sample. One scale, Productivity I, falls below the acceptable criterion of .75 for any one sample. For the purpose of further analyzing inter-rater reliability, Table IV presents a scale-by-scale categorical assessment. It is interesting to note that Productivity $I$, which has more tested and refined items than the Productivity II scale, showed lower reliability. 
TABLE IV

CATEGORICAL ANALYSIS OF RELIABILITY

\begin{tabular}{|c|c|c|c|}
\hline \multirow[b]{2}{*}{ Scale Name } & \multirow[b]{2}{*}{$\begin{array}{l}\text { Denver } \\
\text { Sample } \\
(\mathrm{n}=18)\end{array}$} & \multicolumn{2}{|c|}{ Oregon } \\
\hline & & $\begin{array}{c}\text { ATU } \\
\text { Releasees } \\
\left(n=35^{\prime}\right)\end{array}$ & $\begin{array}{l}\text { BMCC } \\
\text { Students } \\
(n=33)\end{array}$ \\
\hline Client Satisfaction & $\mathrm{H}$ & $\mathrm{H}$ & $n / a$ \\
\hline Alcohol Abuse & M & $\mathrm{H}$ & $\mathrm{H}$ \\
\hline Systems Dependency & M & $\mathrm{H}$ & $\mathrm{H}$ \\
\hline Psychological Distress & $\mathrm{H}$ & $\mathrm{H}$ & $\mathrm{H}$ \\
\hline Legal Difficulties & $\mathrm{H}$ & $\mathrm{H}$ & $\mathrm{H}$ \\
\hline $\begin{array}{l}\text { Interpersonal Isolation-- } \\
\text { Friends }\end{array}$ & $\mathrm{H}$ & M & $\mathrm{H}$ \\
\hline Soft Drug Use & $\mathrm{n} / \mathrm{a}$ & M & $\mathrm{H}$ \\
\hline $\begin{array}{l}\text { Interpersonal Aggression-- } \\
\text { Friends }\end{array}$ & $\mathrm{H}$ & M & M \\
\hline Drug Abuse & $\mathrm{H}$ & M & I \\
\hline Productivity II & $n / a$ & L & $\mathrm{H}$ \\
\hline $\begin{array}{l}\text { Interpersonal Isolation-- } \\
\text { Family }\end{array}$ & $\mathrm{H}$ & I & M \\
\hline Productivity I & M & LL & $\mathrm{H}$ \\
\hline
\end{tabular}

$$
\begin{aligned}
& \mathrm{H}=.89-.98 \\
& \mathrm{M}=.75-.88 \\
& \mathrm{~L}=.56-.74 \\
& \mathrm{~L}=.55 \text { and below }
\end{aligned}
$$


Assessing Reliability Over Time

Correlation coefficients may change over time as a function of increased interviewing skill and experience with the instrument. To separate each sample into two time periods, this researcher utilized the following schema. A clear distinction is made in the community college sample since all scores obtained during the first two weeks are from one group of students $(n=20)$ and the scores from the last week are from another group $(n=13)$. Upon analys is of the demographic data, there appeared to be no major differences between groups and therefore this variable will not be further developed.

For the purpose of this analysis, change in reliability will be defined as a plus or minus difference of .05 between correlation coefficients. A zero displayed in the Change column denotes no change in reliability from time one to time two as presented in Table V. Productivity I, Interpersonal Isolation-Family, and Drug Abuse show positive change for both samples. Interpersonal Aggression--Friends, Legal Difficulties, and Soft Drug Use show positive change for any one sample. No scale shows negative change for both groups. Interpersonal Isolation--Friends, Psychological Distress, Interpersonal Aggression--Friends, Alcohol Abuse, and Productivity II show negative change for any one sample. 
INCREASING RELIABILITY OVER TIME

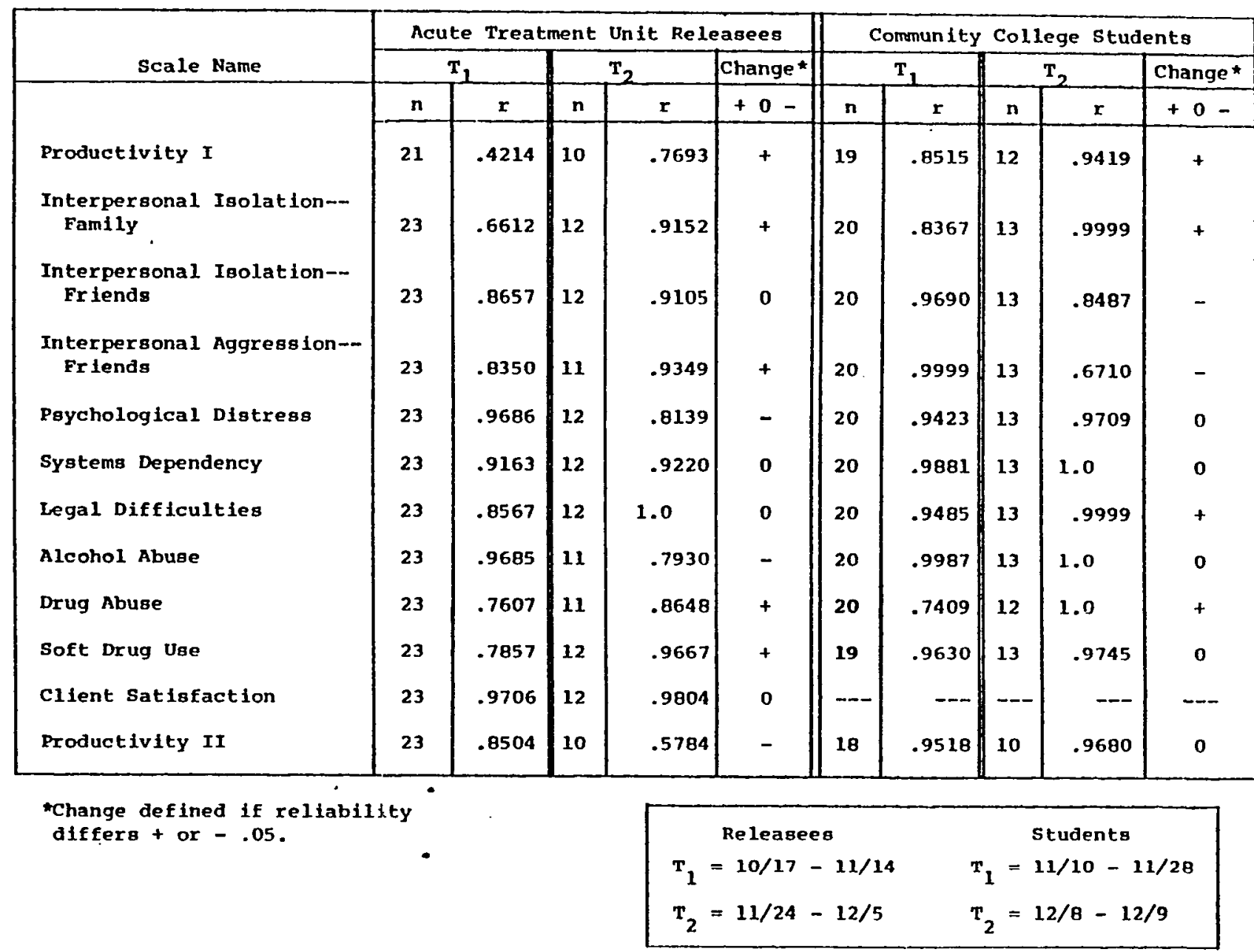




\section{Conclusions}

Upon analysis of the critical areas of the research question, the data indicate that the Multi-Dimensional Outcome Measure demonstrates overall inter-rater reliability. With the exception of Productivity I, all twelve scales manifest acceptable inter-rater reliability. Differences in inter-rater agreement between samples are generally in favor of higher agreement for the student sample than for the inpatient sample. The Drug Abuse scale is the only measure which shows higher reliability for the inpatient releasees (.87 vs. .74). To what this difference can be attributed is unknown at this time. One conjecture would be that the college students may be more reluctant to consistently report use of drugs than the hospital patients. Three scales-Drug Abuse, Productivity II, and Interpersonal Isolation--Family--fall just below the acceptable criterion of .75 but have adequate reliability in the .70 to .74 range. Productivity I when tested with the inpatient sample demonstrates marginal reliability of .55. However, in view of the fact that the Productivity I scale appears to have high correlation in both the Denver sample and the Oregon community college sample, one may conjecture that this measure can be administered with an acceptable degree 
of reliability to community mental health consumers. Some care should be observed when testing inpatient populations. Three scales--Productivity I, Interpersonal Isolation--Family, and Drug Abuse--exhibit an increase in reliability over time for both samples; Systems Dependency shows no change for both groups; and none of the twelve scales show a decrease in reliability for both groups. Two scales, Productivity I and Interpersonal Isolation--Family, demonstrate a positive change from a non-acceptable reliability to acceptable reliability. This would appear to indicate that with additional training and experience, low reliability can be increased to an acceptable level. One may conclude that the MDOM is a reliable and appropriate community mental health outcome measure. 
CHAPTER VI

\section{IMPIICATIONS FOR COMMUNITY MENTAL HEALTH} PROGRAM EVALUATIONS

The purpose of demonstrating inter-rater reliability of the Multi-Dimensional Outcome Measure is to insure its merit as an evaluation tool for community mental health programs. To assist mental health professionals in the ir potential utilization of this instrument, two general areas of discussion will be presented: strengths and weaknesses of the measure and the standardization of the community norm.

\section{STRENGTHS AND WEAKNESSES}

OF THE MDOM

Standardized scales in any measure have the benefit of established validity and are very useful for evaluators who cannot invest time and resources in the construction of their own measures. In the original development of the measure, Interpersonal Aggression--Friends and Legal Difficulties demonstrate low reliability. (Ciarlo and Reihman, 1974) This inter-rater reliability study replicates this experience with the Interpersonal Aggression--Friends scale. In con- 
trast, the Legal Difficulties scale was found to be highly reliable for both inpatient and student respondents. Although the Productivity II scale is still considered experimental, this researcher found the correlation between interviewers to be much greater on this scale than the Productivity I scale. Productivity I for the inpatient sample exhibited the lowest agreement between interviewers of any of the twelve tested scales. It suggests that evaluators fully consider the consequences of low reliability when utilizing this measure with an inpatient population. Throughout the course of the study, this researcher documented the difficulties experienced in the administration of the MDOM. There were three areas of difficulty including: frequently changing time frames, problems of accessibility, and poor wording of questions and responses. The frequent change of time reference throughout the questionnaire may have caused some confusion for respondents. In the first twenty-five items, the time reference is the immediate present. This shifts to within the past few days for Items 26 through 34, within the past year for Items 35 through 64, within the past month for Items 65 to 82, and back to within the past year for Items 83 through 90. In three of the measures, Interpersonal Isolation-Family, Interpersonal Isolation-Friends, and Productivity II, 
questions which purport to measure the degree of isolation or productivity may be measuring accessibility. For example, in Productivity II, those items which pertain to care and discipline of the children (Items 7 and 8 ) do not take note of limited opportunities owing to divorce or separation. Similarly, respondents who have limited opportunity to engage in activities of meal preparation or contributing to the family's money situation by working at home (Items 12 and 15) score low in productivity. Those respondents with less opportunity for contact with family and friends score as more interpersonally isolated. For community mental heaith programs, especially inpatient facilities in rural or semi-rural regions, what the scales may actually be measuring is physical isolation and limited accessibility rather than interpersonal isolation.

Many of the items in the instrument have poorly worded questions or responses. For example, in the Client satisfaction scale, Item 91 does not clearly delineate who the admission person is. It could be a receptionist, doctor, psychiatric aide or social worker. Items 95 and 96 conceptualize client judgment of service in an awkward manner. Productivity II questions pertaining to shopping and money management are not readily applicable for inpatients and are awkward to administer. Interpersonal Isolation, Items 17 
and 21, and Items 19 and 23, appear to have inappropriate responses. It is difficult for a subject to quantify the amount of time spent with family and friends given the choices of "almost all," "about half," "very little," or "hardly ever." In questioning the amount of help and support given by family and friends, no assessment is included as to whether or not a person requests help. In the substance Abuse scales, it is difficult to ascertain if use of alcohol or drugs has caused a problem. Subjects also experience some difficulty in retrospective judgments about whether or not substance abuse was responsible for separation from spouse or job.

In addition to the aforementioned particular difficulties, there are three general limitations inherent in the utilization of the instrument: the recessity for training, the inadequacy of the measure to monitor individual cilent functioning, and the length of the questionnaire. In its present form, the MDOM is not ready for immediate use in community mental health programs. Iimited information is published on the instrument and to insure validity and reliability, interviewers must be trained to administer the instrument. Standardized alternative ways of phrasing questions must be taught. Clinicians who wish to use the measure should contact knowiedgeable resource persons who 
have been adequately trained in the use and analysis of the instrument.

Ciarlo and Reihman stress the utility and versatility of the MDOM in monitoring quality control for a variety of mental health program outcomes. However, the MDOM is most appropriate for analysis of group rather than individual treatment outcomes. To correct this deficiency, Shirley (1975) suggests in her dissertation:

A multi-facetal approach to client outcome program evaluation is preferential to use of a single approach since weaknesses of one approach are likely to be balanced by the strengths of another approach.

The MDOM is comprised of more than ninety questions, excluding any identifying information of the respondents. It takes on the average about thirty minutes to administer. The length of the questionnaire and the necessity for verbal responses limits the use of the measure by excluding the more disturbed persons. It is the opinion of the author that the Multi-Dimensional Outcome Measure is best suited for community programs and has many inherent difficulties when utilized with an inpatient population.

\section{STANDARDIZATION OF THE COMMUNITY NORM}

To substantiate validity and increase the usefulness of the measure, developers of the MDOM collected data on a 
stratified random sample of the Denver community. This Denver community norm provides a base line with which to compare mental health service recipients in terms of socially accepted standards of personal and social functioning. To provide a similar standard for Oregon, Jacqueline Reihman of the Program Evaluation Project and the University of Oregon, collected data from a stratified random sample of both urban and rural populations in Oregon during the summer of 1975. Two hundred and fifty community respondents were selected for interviews on nine of the twelve dimensions: Productivity I, Interpersonal Isolation--Family, Interpersonal Isolation--Friends, Psychological Distress, Drug and Alcohol Abuse, and Soft Drug Use. In addition to these scales, the oregon study included individual items for the experimental Productivity II, Hard Drug Use, and Public Systems Dependency. The purpose of developing a community norm for Oregon was to establish the credibility of the instrument for Oregon urban and rural communities. Information regarding the findings of the Oregon standardization study is incomplete at this time; however, preliminary findings do not appear to significantly differ from the Denver norm and the same mean of 50 and the standard deviation of 5 are applicable. (Brodsky, 1975)

To illustrate the utilization of the community norm, 
the mean scores for inpatient releasees and community college students have been standardized and charted in Figure I (for raw scores, see Appendix C). Inpatient admissions sampled under similar field conditions have also been included (see Appendix D for case study).

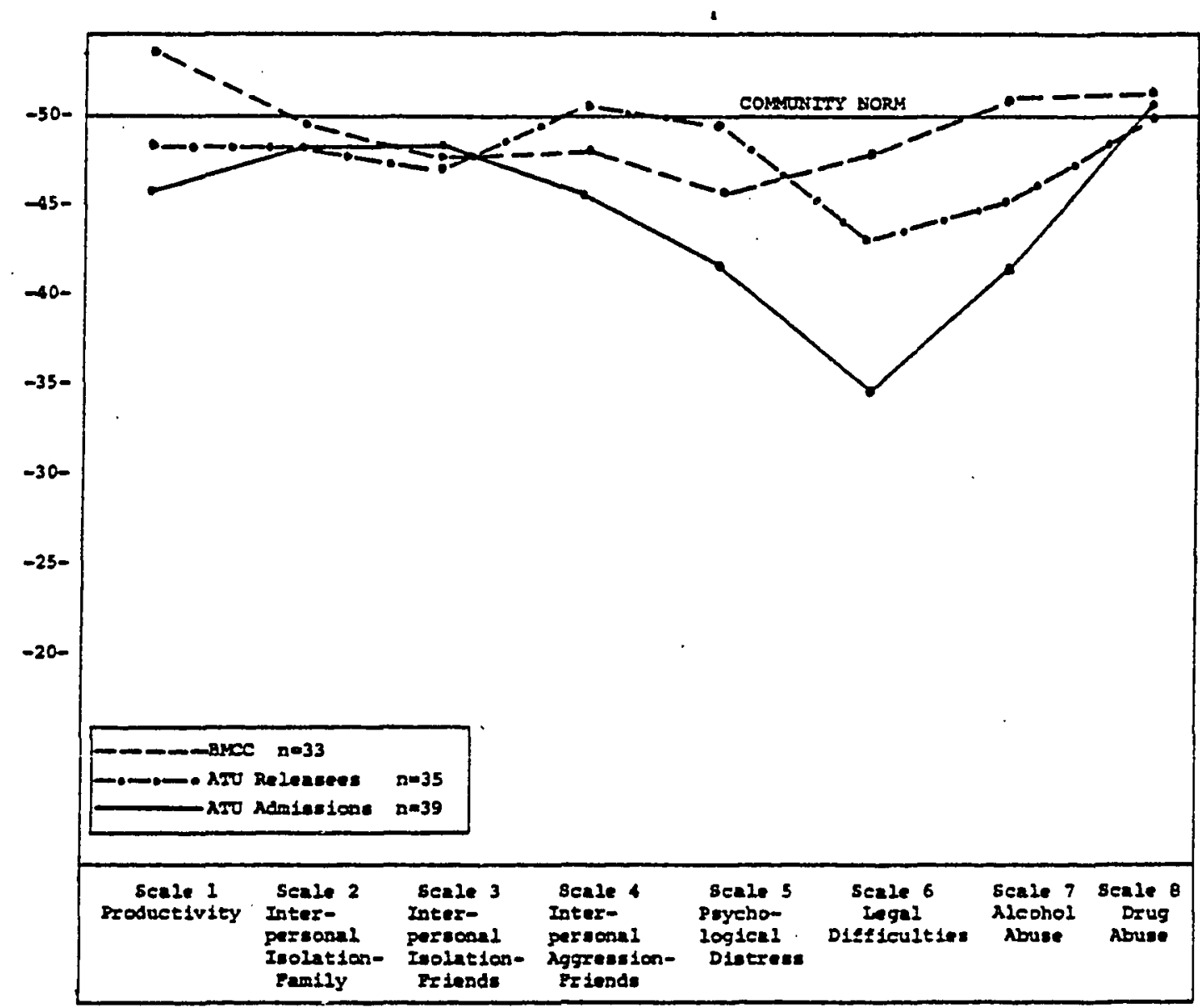

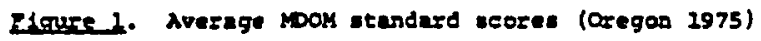


One would predict that respondent scores would be progressively in the direction of more favorable outcome as one progresses from admission to student scores. An exception to this thesis is scale number 5, Psychological Distress. Inpatient releasees show a more favorable outcome than do admissions; however, college students exhibit more distress than do the inpatient releasees. This is significant at the .05 level (two-tail "t" test). This data may be attributed to the time period during the study. The college students were interviewed toward the end of the term when papers and finals exert pressure. It might also be indicative of the life stage in which the typical student finds himself: single, recently away from home, engaged in issues of identity, confusion, and resolution. These are only conjectures and are given as possible interpretations of the data.

The Multi-Dimensional Outcome Measure is an important advancement in mental health program evaluation. Its advantages of comprehensive behavior assessment far outweigh the inherent limitations in the construction and administration of the measure. It is hoped that by presenting these examples in the utilization of the MDOM, others may be encouraged to apply the instrument in similar field settings. 
Brodsky, Gerald. "Memorandum on MDOM Information." November 25, 1975. Management Support Services, Mental Health Division, Salem, Oregon. (Xeroxed)

Ciarlo, James A. "Mental Health Evaluation Systems: Supporting Comprehensive Decision Making." Presentation at the Second Annual Workshop on Program Evaluation of Region X ADAMHA and the Program Evaluation and Development Project, Portland, Oregon. April 11, 1975.

Ciarlo, James A. "Monitoring of Outcome Data: Steps Toward a System for Improving Mental Health Program Outcomes." Unpublished paper presented at the American Psychological Association Convention, Montreal, Canada, September, 1975.

Ciarlo, James A.; Lin, Shie-fang; Bigelow, Douglas; and Biggerstaff, Marilyn. "A Multi-Dimensional Outcome Measure for Evaluating Community Mental Health Programs." Unpublished paper presented at the American Psychological Association Convention, Honolulu, Hawaii, 1972 .

Ciarlo, James A. and Reihman, Jacqueline. "The Denver Community Mental Health Questionnaire: Development of a Multi-Dimensional Program Evaluation Instrument." Unpuilished. Denver Mental Health Systems Evaluation Project of the Northwest Denver Mental Health Center and the University of Denver, 1974. (Xeroxed)

Hardison, James C. "An Assessment of Community Mental Health Program Evaluation/Informational Needs in the State of Oregon." Salem, Oregon: Manpower Evaluation and Utilization Office of the Mental Health Division, July, 1975. (Xeroxed)

Hargreaves, William A.; Attkisson, C. C.; McIntyre, M. H.; Siegel, I. M.; and Sorensen, James E., eds. Resource Materials for Community Mental Health Proaram Evaluation: Elements of Program Evaluation, Volume I. Rockville, Maryland: National Institute of Mental Health, 1974 . 
Hargreaves, William A.; McIntyre, M. H.; Attkisson, C. C.; and Siegel, I. M. Resource Materials for Community Mental Health Program Evaluation: Evaluating the Effectiveness of Services, Volume IV. Rockvilie, Maryland: National Institute of Mental Health, 1975.

"The Muiti-Dimensional Outcome Measure: Training Manual." Salem, Oregon: Manpower Evaluation and Utilization Office of the Mental Health Division, 1975. (Xeroxed)

Reihman, Jacqueline. Manpower Evaluation and Utilization Office of the Mental Health Division, Salem, Oregon. Consultations during September, November, and December, 1975 .

Reihman, Jacqueline. "MDOM Standardization Study in oregon." Presented at the Second Annual Mental Health Conference on Program Evaluation and Research, Portland, Oregon, August 5, 1975.

Shirley, Ruth E. "Client Outcome, Program Evaluation and Functional Role Analysis in a Community Mental Health Clinic." Unpublished Ph.D. dissertation, Oregon State University, 1975.

Suchman, Edward A. Evaluation Research. New York: Russell Sage Foundation, 1967. 
APPENDICES 


\section{APPENDIX A}

MULTI-DIMENSIONAL OUTCOME MEASURE

MDOM

Checklist

-who you are

--where from

-why

-content

--time involvement

--confidentiality

--arrangements

--consent

-receipt

-release follow-up 
MULTI-DIMENSIONAI OUTCOME MEASURE

Name or Number:

County:

Social Worker:

Date of Admission:

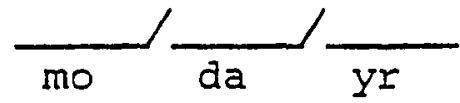

Blue Mountain Community College Student

Date of Release: $\frac{}{\mathrm{mo}} / \frac{}{\mathrm{da}} / \frac{\mathrm{yr}}{\mathrm{y}}$ Day Night

\begin{tabular}{|c|c|c|c|}
\hline Married & Single & Sex: & Male \\
\hline Divorced & Widowed & & Female \\
\hline separated & Other & Age: & \\
\hline
\end{tabular}

Interviewer:

Date of Interview:

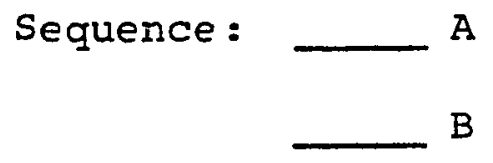

Comments: 
We would like to ask you some questions regarding your activities both in and out of your home.

1. How often do you visit, speak, or correspond with friends who live away?

$\angle I F$ NO FRIENDS LIVE OUT OF TOWN, IEAVE BLANK

Once a day Once/twice week Several times Never to once a month a year

2. Do you work at a job?

$\triangle$ SELF-EMPLOYED IS ACCEPTABLE. HOUSEWIFE IS NOT

Full-time Part-time Irregularly Not employed

3. Is your salary different now from what it was three months ago?

Much more Slightly more About the same Less than before

4. Do you have any time that you spend in volunteer-type activities?

More than 20 8-20 hours $1-7$ hours None

5. Do you take any classes, job training, etc., and if so, how much time do you spend per week?

INCLUDE TIME BOTH IN AND OUT OF CILASS./

More than 20 8-20 hours $1-7$ hours None

6. How much of the housework or cleanup do you do?

A11 Most Some None

I.D.1. Do you have any children? Y_ Yes No $\overline{\text { EXCLUDE WOMEN WHO HAVE GIVEN CHIID UP FOR ADOPTION./ }}$ $\angle S C O R E$ AS "NO" 
How many children are in each age range?

$\begin{array}{ll}\text { Pre-School } & \text { High School } \\ \text { Grade School } & \quad \text { Post High School }\end{array}$

$/ \overline{\text { IF CLIENT HAS NO CHILDREN, OR NO CHILDREN OF HIGH } /}$ /SCHOOL AGE OR BELOW, LEAVE QUESTIONS 7 AND 8 BLANK/ $\angle A N D$ SCORE AS "2" ON THE CODING GUIDE.

7. How much of the caring of the children are you responsible for?

EMPHAS IZE EMOTIONAL CARE OVER FINANCIAL CARE.

All Most Some None

8. How much of the discipline of the children are you responsible for?

All Most Some None

9. How much of the household money management do you do?

Al1 Most Some None

10. How much of the shopping for the household do you do? (Groceries, Furnishings, Supplies, eto.)
AII
Most
Some
None

11. How many hours of TV do you usually watch a day? (24 hour period)

None $\quad 1-2 \quad 3-5 \quad 6$ or more

EXCLUDE \#12 FOR HOSPITAL POPULATION./

12. How much do you contribute to the family's money situation by working at home?

$\overline{\text { E.G. MAKING OR SELIING CRAFT OBJECTS, BABY-SITTING, }}$ /MAKING CLOTHES. AS DISTINCT FROM BEING SELF-EMPLOYED/ $\angle A N D$ WORKING AT HOME. 


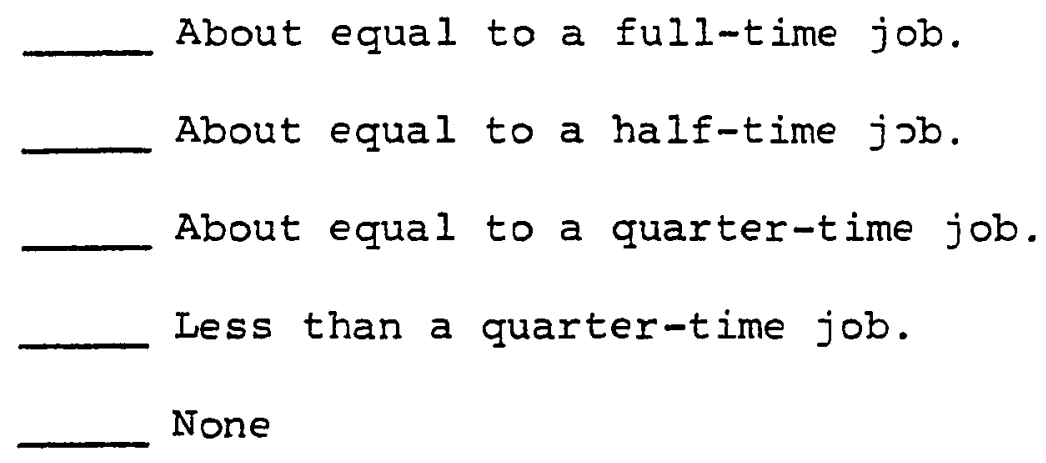

13. How many hours weekly do you spend in doing hobbies, crafts, or sports activities?

E.G. KNITTING, GARDENING, STAMP COLLECTING, ETC.,

LSEPARATE O.T. FROM FREE TIME.

$$
9 \text { or more } 5-8 \quad 2-4 \quad 0-1
$$

14. How many hours do you generally sleep a day?

$$
8 \text { or less } 9 \quad 10 \quad 11 \text { or more }
$$

$\angle$ EXCLUDE \#15 FOR HOSPITAL POPULATION.

15. How many hours a day do you spend in the preparation of meals?

3 or more About 2 About 1 Less than 1

THE NEXT GROUP OF QUESTIONS DEAL WITH YOUR RELATIONSHIPS WITH YOUR FRIENDS AND YOUR FAMILY. WE SHOULD IIKE TO KNOW SOMETHING ABOUT THE TIME YOU SPEND WITH YOUR FAMILY AND FRIENDS.

16. How many family members live with you?

/FOR HOSPITAL POPULATION: IMMEDIATELY PRIOR TO HOSPI-/

LTALIZATION. QUESTION 16 ONLY.

$$
6 \text { or more } \quad 3-5 \quad 1-2 \quad \text { None }
$$

17. How much of your free time do you spend with your family? /THIS REFERS TO PRIMARY FAMILY. IF. NO FAMILY, LEAVE/ $\angle B L A N K$. FREE TIME DEF INED AS UNCOMMITTED TIME.
Almost all
About half
Very little
Hardly ever 
18. How often do you visit or speak with family members not living with you?

/EMPHASIZE WRITTEN CORRESPONDENCE. IF NO FAMILY,/

LIEAVE BLANK.

Once a day Once/twice a week Several times Never to once a month. a year

19. How much would your family be of help and support to you if you found yourself in trouble?

/REFERS TO PRIMARY FAMILY. HELP AND SUPPORT DEFINED AS/ LEMOTIONAL AND/OR FINANCIAL. IF NO FAMILY, LEAVE BLANK/

A great deal Quite a bit Little Not at all

20. How many close friends do you have?

$\longdiv { \text { MAY INCLUDE IDEA OF RECIPROCITY IN DEFINITION OF/ } }$

$\angle$ "CLOSE".

6 or more $3-5 \quad 1-2$ None

21. How much of your free time do you spend with your Eriends?

Almost all About half Very little Hardly ever

22. How many of your neighbors do you speak to?

$\angle$ REFERS TO NUMBER OF PEOPLE, NOT HOUSEHOLDS./

6 or more $3-5 \quad 1-2$ None

23. How much help and support would your friends be to you if you found yourself in trouble?

LHELP AND SUPPORT DEFINED AS FINANCIAI AND/OR EMOTIONAL/

A great deal Quite a bit Iittle Not at all

24. When you are with your friends, how often do you argue with them?

Never Seldom Often Constantly 
25. When you are with your friends, how often do you physically fight?

Never Seldom Often Constantly

THE NEXT NINE QUESTIONS CONCERN HOW YOU HAVE BEEN FEELING IN THE PAST FEW DAYS, SO PIEASE THINK BACK AND ANSWER THESE QUESTIONS IN TERMS OF JUST THE PAST FEW DAYS.

26. In the past few days, how often have you felt fearful ox afraid?

Never Once or twice Often Almost always

27. In the past few days, how often have you felt sad or depressed?

Never Once or twice often Almost always

28. In the past few days, how often have you felt angry?

Never Once or twice Often Almost always

29. In the past few days, how often have you felt mixed-up or confused?

Never Once or twice Often Almost always

30. In the past few days, how often have you felt tense?

Never Once or twice Often Almost always

31. In the past few days, how often have you had trouble sleeping?

Never Once or twice Often Almost always

32. In the past few days, how often have you had trouble with poor appetite?

Never Once or twice Often Almost always

33. In the past few days, how often have you had trouble with indigestion?

Never Once or twice Often Almost always 
34. In the past few days, how often have you had trouble with Eatique?

Never Once or twice Often Almost always

IN THE PAST YEAR, WHICH OF THE FOLLOWING AGENCIES HAVE YOU RECEIVED OR SOUGHT SERVICES FROM?

35. County Public Welfare Department

36. Food Stamps

37. County Health Department

38. Family Planning Clinic

39. Iegal Aid

40. Division of Vocational Rehabilitation

41. Oregon State Employment Service

42. Manpower Development and Training Program

43. Alcohol and Drug Abuse Program

44. Social Security

45. Children's Services Division

46. County Juvenile Department

47. Salvation Army

48. Community Mental Health Center

49. State Mental Hospital

50. Retired Seniors Volunteer Program

51. Action for the Handicapped, Inc.

52. Cinurch or Religious Organization

53. Other: 
54. Other:

55. Other:

56. Other:

57. Other:

58. Other:

59. Other:

THE NEXT FEW QUESTIONS CONCERN ANY LEGAL PROBLEMS YOU MAY HAVE HAD IN THE PAST YEAR.

I.D.2. Have you been arrested at all in the last year? Y Yes No

I.D.3. Have you been in jail in the past year?

$$
\begin{aligned}
& \text { NeS } \\
& \text { IF NO TO BOTH I.D.2. AND I.D.3., GO TO QUESTION } 64 /
\end{aligned}
$$

60. How many times in the past year have you been arrested on intoxication-related charges?

COUNT DUIL HERE, NOT UNDER MOVING TRAFFIC VIOLATIONS'

Never Once or twice $3-5$ times 6 or more times

61. How many times in the past year have you been arrested for illegal possession of drugs?

Never Once or twice $3-5$ times 6 or more times

62. How many times in the past year have you been arrested for loitering or vagrancy?

Never Once or twice 3-5 times 6 or more times

63. How many times in the past year have you been arrested for anything else?

Never Once or twice 3-5 times 6 or more times 
64. How many times in the past year have you been cited for moving traffic violations?

$\angle D O$ NOT INCLUDE DUIL.

Never Once or twice 3-5 times 6 or more times

THE NEXT GROUP OF QUESTIONS DEAL WITH YOUR USE OF ALCOHOL AND DRUGS. TIME REFERENCE IS WITHIN THE LAST MONTH FOR INPATIENT ONE MONTH PRIOR TO HOSPITAIIZATION.

I.D.4. Do you drink alcoholic beverages? Yes No $\angle$ IF NO, GO TO I.D.5.

65. If yes, to I.D.4., how often do you get intoxicated? Never Once or twice a month Once or twice a week Every day $\angle$ IS THERE A PRIMARY FAMILY?

66. When you use alcohol, does it cause any problems with your spouse?

IF NO SPOUSE, LEAVE BIANK, UNLESS SEPARATION WAS A/ $\angle R E S U L T$ OF ALCOHOL PROBLEM.

Never Sometimes often Almost always

67. When you use alcohol, does it cause any problems with your children or parents?

IF NO CHILDREN OR PARENTS, LEAVE BLANK.

68. When you use alcohol, does it cause any problems with your friends?

IF NO FRIENDS, SCORE "ALMOST ALWAYS"./ 
69. When you use alcohol, does it cause any problems with your employer?

IF NO JOB, SCORE "ALMOST ALWAYS". IF JOB LOSS WAS DUE/

$\angle T O$ ALCOHOL PROBIEM. OTHERWISE, IEAVE BIANK.

Never Sometimes Often Almost Always

70. When you use alcohol does it cause any problems with your self?

Never Sometimes Often Almost Always

71. When you use alcohol, does it cause any problems with your physical health?

Never Sometimes Often Almost Always

I.D.5. Have you ever used or are you now using Antabuse? Yes $\frac{\text { No }}{\angle I F \text { NO, GO TO I.D.6. }}$

72. Dosage? Milizigrams

73. How long have you used it? Weeks (round to closest whole number)

74. How often did you use Antabuse?

Once/twice a week Three times a week

Every day Other

75. When you used Antabuse, did you drink? ___ Yes___ No If yes, what was your reaction?

I.D.6. Do you use any drugs or medications prescribed or not, of any kind other than alcohol or Antabuse? 
ASSESS IF USE SUGGESTS A PROBLEM. USE TIME /REFERENCE WITHIN THE LAST MONTH. FOR INPATIENT/ $\angle O N E$ MONTH PRIOR TO HOSPITALIZATION.

Yes What kind?

For what?

No

$\angle I F$ CLIENT RES PONDS "NO" TO I.D.6., GO TO 83.

76. If "yes" to I.D.6., how often do you use drugs?

Never Once/twice a month Once/twice a week

Every day

77. When ycu use drugs, does it cause any problems with your spouse?

/IF NO SPOUSE, LEAVE BLANK, UNLESS SEPARATION WAS/ $\angle R E S U L T$ OF DRUG PROBLEM.

Never Sometimes Often Almost Always

78. When you use drugs, does it cause any problems with your children or parents?

$\angle I F$ NO CHILDREN OR PARENTS, LEAVE BLANK./

Never Sometimes Often Almost Always

79. When you use urugs, does it cause any problems with your friends?

IF NO FRIENDS, SCORE "ALMOST ALWAYS."

Never Sometimes Often Almost Always 
80. When you use drugs, does it cause any problems with your employer?

/IF NO JOB, SCORE "ALMOST ALWAYS". IF JOB ILOSS WAS DUE/

$\angle T O$ DRUG PROBLEM. OTHERWISE LEAVE BLANK.

Never Sometimes Often Almost Always

81. When you use drugs, does it cause any problems with your self?

Never Sometimes Often Almost Always

82. When you use drugs, does it cause any problems with your physical health?

Never Sometimes Often Almost Always

THE NEXT GROUP OF SPECIFIC DRUG QUESTIONS ARE WITHIN THE CONTEXT OF THE LAST YEAR.

NOTE TO INTERVIEWER: IF YOU DO NOT KNOW THE DRUG CATEGORY, /PLEASE WRITE DOWN THE DRUG NAME AND WE'LI CHECK IT WHEN YOU/ $\angle$ RETURN.

83. How often have you used tranquilizers?

Never Once/twice Once/twice Once/twice a a year a month week or more

Was it prescribed?

All of it Some None

84. How often have you used Amphetamines? ("uppers")

Never Once/twice Once/twice Once/twice a a year a month week or more

Was it prescribed? ___ All of it __ Some None

85. How often have you used Barbiturates? (Sedatives, sleeping pills, "downers")

Never Once/twice Once/twice Once/twice a a year a month week or more

Was it prescribed? AII of it Some None 
86. How often have you used Codeine? (including cough syrup)

\begin{tabular}{|c|c|c|}
\hline ever & Once/twice & Once/twice \\
\hline
\end{tabular}

Was it prescribed?

A11 of it Some

None

87. How often have you used Heroin, Opium, or Morphine? ("snow)

Never Once/twice Once/twice Once/twice a a year a month week or more

Was it prescribed? All of it Some None

88. How often have you used Marijuana?
Never
Once/twice
Once/twice
Once/twice a
a year
a month
week or more

89. How often have you used Psychedelics? (ISD, Mescaline, STP, "Acid")
Never
Once/twice
Once/twice
Once/twice a
a year
a month
week or more

90. How often have you used Cocaine?
Never
Once/twice
Once/twice
Once/twice a
a year
a month
week or more

\section{AFTER DISCHARGE}

OUR FINAL GROUP OF QUESTIONS CONCERNS HOW YOU FEEL ABOUT THE TREATMENT YOU HAVE RECEIVED AT THE CIINIC OR HOSPITAL.

91. When you came to the hospital/clinic, did the admission person make you feel comfortable?

$\begin{array}{llll}\text { Very } & \text { Quite } & \text { Somewhat } & \text { Not at all } \\ \text { Comfortable } & \text { Comfortable } & \text { Comfortable } & \text { Comfortable }\end{array}$

92. Did you get the kind of services you wanted?

Definitely yes somewhat I don't know Not at al1 
93. Were you satisfied with the services you received?

Very satisfied Satisfied Indifferent Dissatisfied

94. Do you feel differently about your problem(s) now?

A great deal Somewhat better No change Worse

95. Was this due to the services you received at the hospital/clinic?

$$
\begin{aligned}
& \text { Yes, all of it Yes, most of it } \\
& \text { Yes, part of it } \quad \text { No }
\end{aligned}
$$

96. If you were to seek help again and hospitalization were recommended, would you come back to the hospital/clinic?

Definitely yes Depends

I don't know Definitely not

I.D.7. What is your primary source of income?

Employment Self-Support

Family Support Public support 
CONSENT FOR FOLLOW-UP STUDY

I understand that the Eastern Oregon Comprehensive Community Mental Health Center staff is concerned about my continued well-being after release from Eastern Oregon Hospital and Training Center. I further understand that staff of Eastern Oregon Comprehensive Community Mental Health Center will be concerned that I am receiving the services I need and would like to visit me in my home about 90 days after my release from the hospital to repeat the interview I have just completed. I further understand that my responses to that interviewer will be held confidential and will not be released without my permission.

I hereby agree to be contacted for a follow-up interview after my release from Eastern Oregon Hospital and Training Center.

Signed

Date 
Name or Number:

(C. 4-8)

Team:

(C. II)
McCallig -1
McGowan -2
Johnston -3

County:

$$
\text { (C. 9-10) }
$$

Diagnos is :

$$
\begin{aligned}
& \text { Petty }-4 \\
& \text { Other }-5 \\
& \text { DNA }-9
\end{aligned}
$$

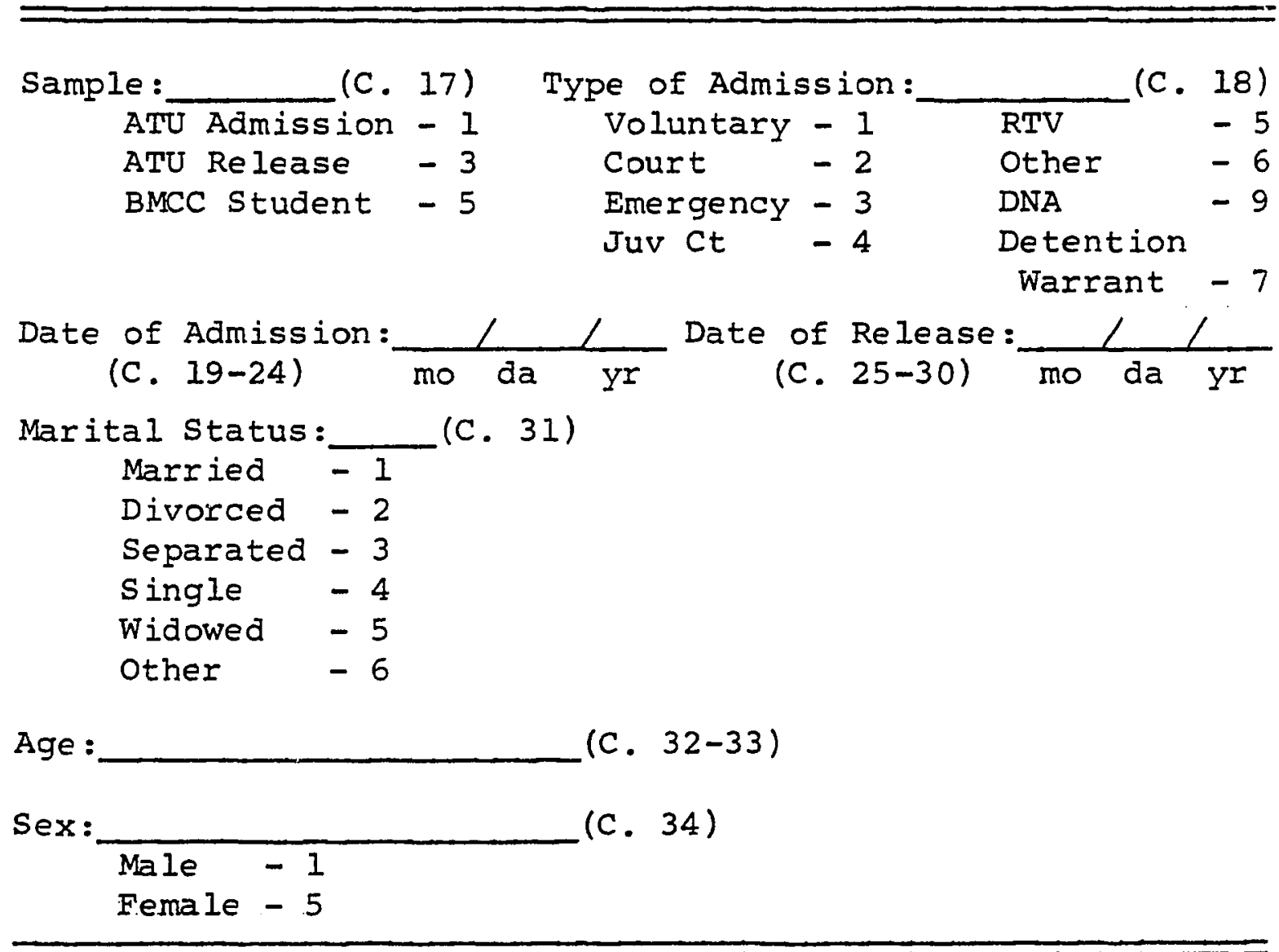


Date of Interview:

(C. 35-40)

Interviewer :

(C. 41)

$$
\begin{aligned}
& \text { Randy - } 1 \\
& \text { Grace - } 2
\end{aligned}
$$

Sequence :

$$
\begin{aligned}
& A-1 \\
& B-2
\end{aligned}
$$

(C. 42 )

Note: Inless otherwise coded, score left to right; score All - 0, Most - 1, Some - 2, None - 3 .

SCALE 1

Item

Housework

Number of Children (Code actual number of children: If more than 9, code 9; if no children, code 0 )

0-6 years Pre-School 1-6 grade Grade School 6-12 grade High School Post High School

Caring: (If no children, score 2, Otherwise: All-0, Most-1, Some-3, None-4)
Item No. Score

6

(C. 47) 
$\underline{\text { Item }}$

Item No. Score

Discipline: (no children score as

8

(C. 53)

2 , otherwise as above ques.)

Money Management: (Score Al1-0,

9

(c. 54)

Most-1, Some-2, None-3i

Shopping:

10

(c. 55)

TV:

11

(c. 56)

Work at Home: (Omit for inpatient sample)

Hobbies:

13

(C. 58)

Sleep:

14

(C. 59)

Meal Preparation: (Omit for

15

(C. 57)

inpatient sample)

SCALE 2

INT PER - FAMILY
ISOLATION

Item No. Score

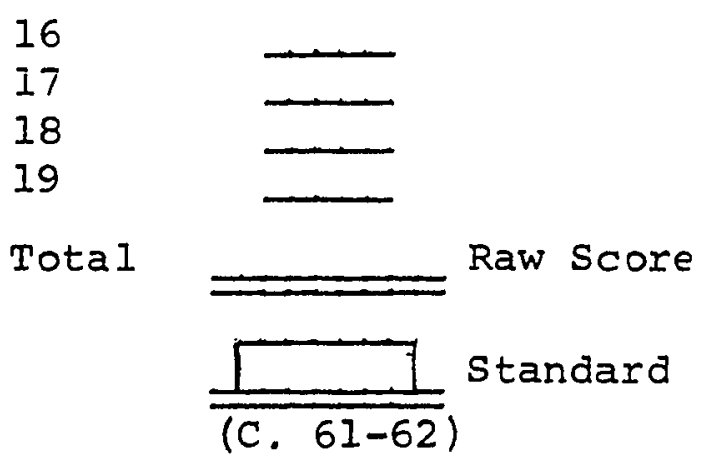


SCALE 3

INT PER - FRIENDS
ISOLATION

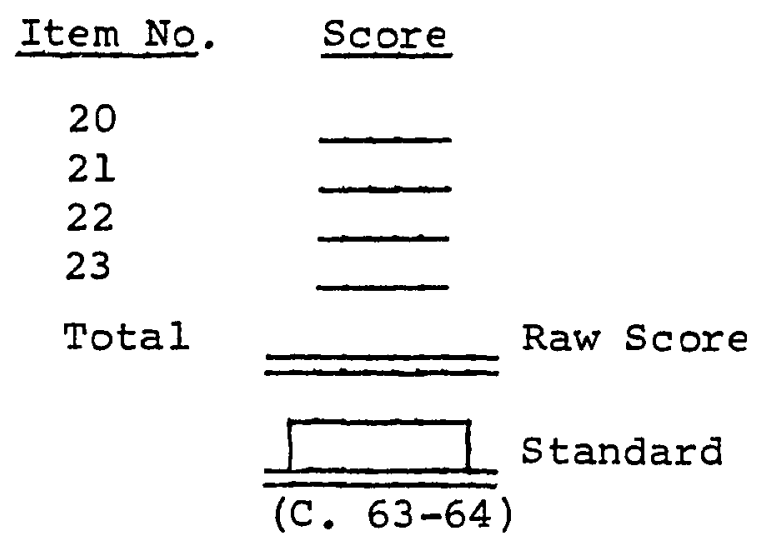

SCALE 4

INT PER AGG - FRIENDS

Item No. Score

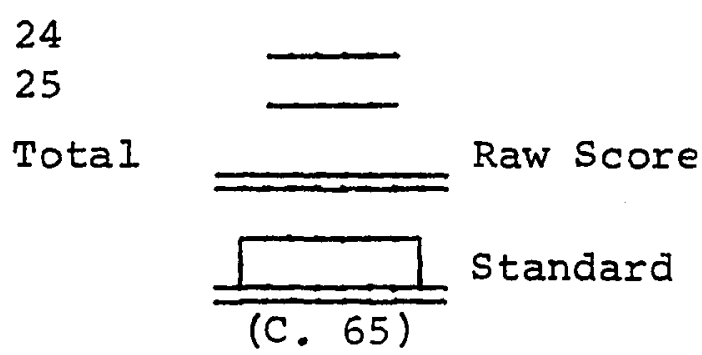

SCALE 5

PSYCH DISTRESS

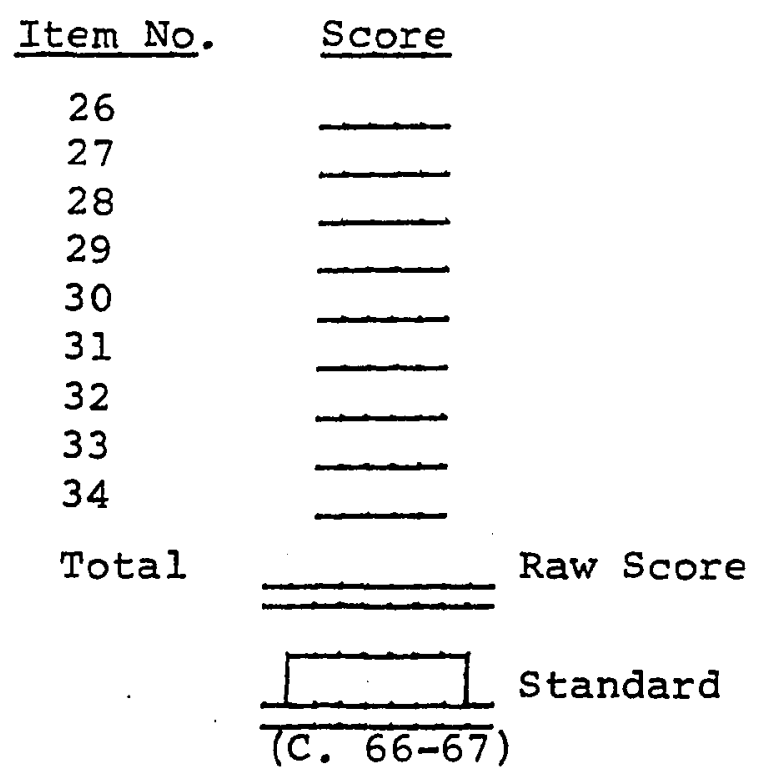


SYS DEP

Score all items, 35-59: No - 0, Yes - 3

Item

Item No. Score

Co. Public Welfare Dept.

35

Food Stamps

36

Co. Health Department

37

Family Planning Clinic

38

Legal Aid

39

Div. of Voc. Rehab.

40

Ore. St. Employ. Svc.

41

Mpr. Dev. \& Trng. Prog.

42

Alcohol \& Drug Abuse

43

Social Security

44

Children's Svc. Div.

45

Co. Juvenile Dept.

46

Salvation Army

47

Comm. Mental Health $\mathrm{Ce}$.

48

State Mental Hospital

49

Retired Sen. Vol. Prog.

50

Action for Handicapped

51

Church or Religious Org.

52

Other:

53

Other:

54

Other: 
Item

Other:
Item No. Score

59

Tota1--Raw Score

Standard

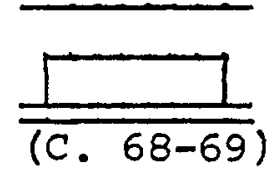

SCAIE 6

LEGAL DIFFICULTIES

(If items skipped, score 0)

Item No. Score

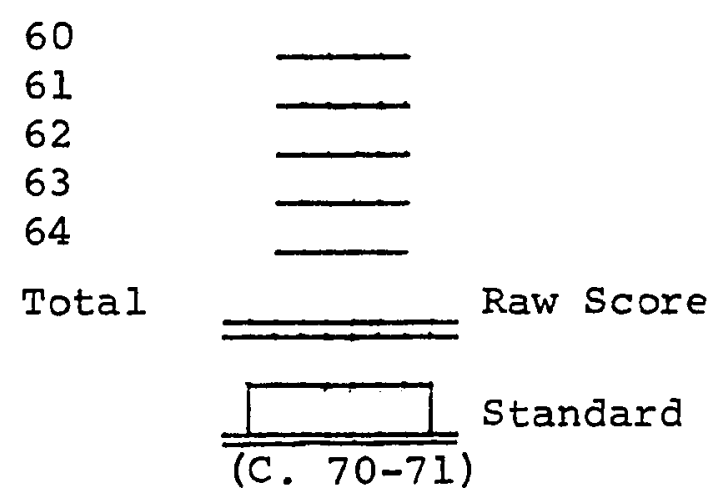

Item

Arrested

No 0

Yes 1

Jail

No 0

Yes 1

C. 74-78:
Item No. Score

$$
\text { I.D.2. }
$$$$
\text { (C. } 72 \text { ) }
$$

I.D.3.

(C. 73) 
Begin Card 02

SCALE 7

ALCOHOL ABUSE

If Client denies any use of Alcohol, score items 65-71 as minus $I^{\prime} \mathrm{s}(-I$ 's). (If no on I.D.4.)

Item No. Score

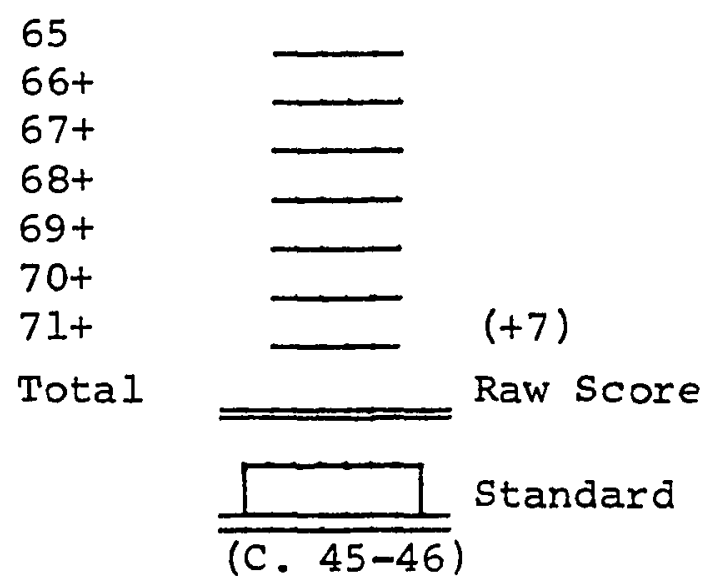

I.D.4.

Drink Alcohol

(C. 47$)$

No -0

Yes - 1

Antabuse

Item

Score

I.D.5.

No -0

Yes - 1

72

Dosage in Milligrams

$\mathrm{DK}=000$

73

No. weeks used

(C. 52-53)

74

Other-0; Once/Twice/wk-1;

(C. 54)

3 times/wk-2; Every day -3

75

(C. 55)

No -0

Yes - I 
SCALE 8

DRUG ABUSE

If Client denies any use of drugs, score item 76 as "O" and items 77-82 minus 1 (-I's). (If no on I.D.6.)

Item

76

$77+$

$78+$

$79+$

$80+$

$81+$

$82+$

Total
Item

I.D.6.

Drug Use

No - 0

Yes - 1
Score

$\overline{(C .58)}$
$(+6)$

Raw Score

Standard

Heroin Use

$$
\text { (Frequency) (Prescribed Score) = Score }
$$

87

$\mathrm{X}$

SCALE 9

SOFT DRUG USE

(Frequency)

(Prescribed Score) $=$ Score

84 $\mathrm{X}$ $=$

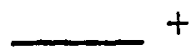

85 $\mathrm{x}$ $=$

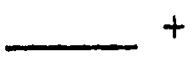

86 $\mathrm{X}$

2

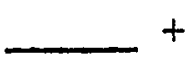

88 $\mathrm{x}$ 2 $=$

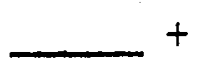

89 $\mathrm{X}$ $=$ $+$

Total

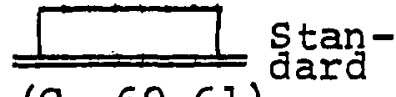


Tranquilizers

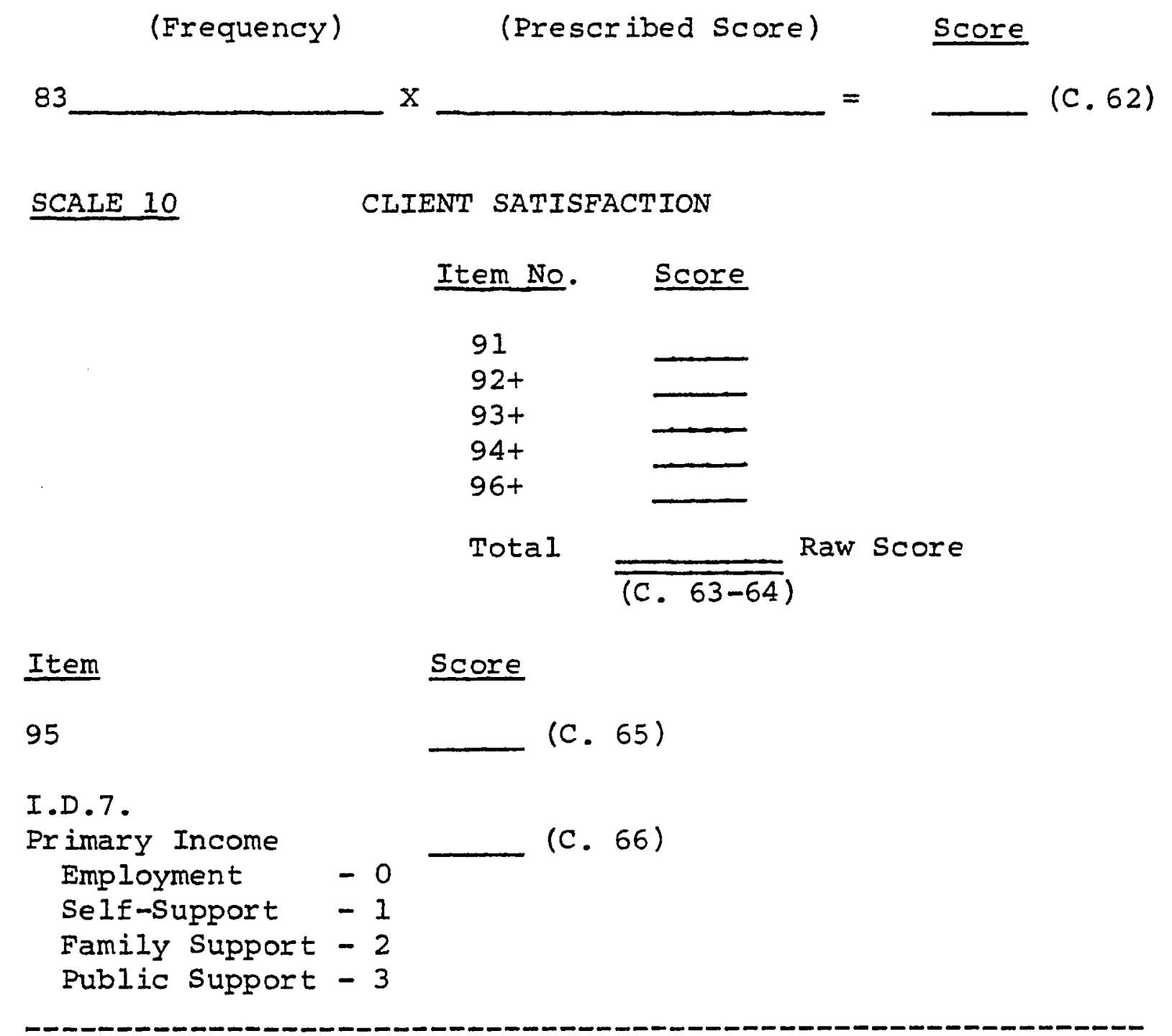

C. $67-78$ Blank

Card No. 02 (C. $79-80$ ) 
APPENDIX C

TABIE VI

\begin{tabular}{|c|c|c|c|c|c|c|c|c|c|}
\hline & \multicolumn{6}{|c|}{$\begin{array}{l}\text { MEAN SCORES ON MDOM SCALES } \\
\text { OREGON SELECTED SAMPLES }\end{array}$} & \multirow{2}{*}{\multicolumn{3}{|c|}{$\begin{array}{l}\text { Blue Mountain } \\
\text { Community College }\end{array}$}} \\
\hline & \multicolumn{3}{|c|}{$\begin{array}{c}\text { ATU } \\
\text { Admissions }\end{array}$} & \multicolumn{3}{|c|}{$\begin{array}{c}\text { ATU } \\
\text { Releasees } \\
\end{array}$} & & & \\
\hline & $\mathbf{n}$ & $\bar{x}$ & SD & $\mathrm{n}$ & $\bar{x}$ & SD & $\mathbf{n}$ & $\bar{x}$ & SD \\
\hline Productivity I & 37 & 11.67 & 2.03 & 31 & 10.55 & 2.08 & 32 & 8.06 & 1.98 \\
\hline $\begin{array}{l}\text { Interpersonal } \\
\text { Isolation--Family }\end{array}$ & 37 & 4.54 & 1.92 & 35 & 4.57 & 1.65 & 33 & 3.82 & 1.13 \\
\hline $\begin{array}{l}\text { Interpersonal } \\
\text { Isolation--Friends }\end{array}$ & 38 & 4.45 & 2.69 & 35 & 4.89 & 2.85 & 33 & 4.76 & 2.38 \\
\hline $\begin{array}{l}\text { Interpersonal } \\
\text { Aggression-Friends }\end{array}$ & 39 & .77 & .96 & 34 & .29 & .58 & 33 & .58 & .61 \\
\hline $\begin{array}{l}\text { Psychological } \\
\text { Distress }\end{array}$ & 39 & 9.49 & 4.82 & 35 & 4.94 & 4.54 & 33 & 7.06 & 3.94 \\
\hline Systems Dependency & 38 & 13.26 & 8.64 & 35 & 9.69 & 5.73 & 33 & 5.27 & 6.45 \\
\hline Legal Difficulties & 39 & 1.69 & 1.72 & 35 & .94 & 1.23 & 33 & .39 & .61 \\
\hline Alcohol Abuse & 39 & 11.79 & 6.76 & 35 & 10.17 & 6.87 & 33 & 5.85 & 4.18 \\
\hline Drug Abuse & 38 & 2.76 & 5.02 & 31 & 3.55 & 5.74 & 32 & 2.56 & 4.24 \\
\hline Soft Drug Use & 39 & 3.74 & 6.52 & 35 & 2.00 & 4.70 & 32 & 3.69 & 5.80 \\
\hline Productivity II & 36 & 19.97 & 5.13 & 33 & 19.88 & 4.17 & 28 & 16.54 & 4.52 \\
\hline Client Satisfaction & $n / a$ & $\mathrm{n} / \mathrm{a}$ & $n / a$ & 35 & 3.46 & 3.71 & né & $n / a$ & $n / a$ \\
\hline
\end{tabular}




\title{
APPENDIX D
}

\section{USE OF THE MDOM IN DETERMINING PROGRAM EFFECTIVENESS :}

\section{A CASE STUDY}

\begin{abstract}
Concommitant with the inter-rater reliability study, this researcher collected data from Acute Treatment Unit inpatient admissions within seven days of admission. of forty-four attempted interviews, thirty-nine were completed, with the hopes of providing a pre-post test study between matched samples of admissions and releasees. To determine if the samples were matchable, client characteristics were tested using Chi Square. While entire samples of admissions and releasees could not be matched, it was possible to match twelve respondents on the basis that they were both admissions and releasees within the six-week period. Although one cannot hope to use this pre-post application of the MDOM to indicate long range good outcomes, it does satisfactorily demonstrate the applicability of the outcome measure.
\end{abstract}

\section{Method}

The administration of the interviews was during conditions identical to the aforementioned reliability study, 
with the exception that a single interview was administered. The researcher obtained a listing from the medical records of the daily admissions during the period from october to November, 1975. Every admission during that time period was a potential respondent. Those subjects unable to comprehend the content of the questionnaire and make verbal responses as well as those admissions with physical problems severe enough to be placed in the surgical ward, were excluded from the sample. Of the thirty-nine completed interviews, a matched sample of twe lve admissions and releasees was selected.

Results

The twelve matched pairs were predominantly male respondents, 83.3 percent, with three-fourths in the divorced separated marital status. The remaining respondents were evenly divided among single, married, and widowed categories. The age data showed a range of 25 to 58 years, a median of 52.5, and a mean of 48.7. Three-fourths of the sample were voluntary commitments, with detention warrant and court and involuntary commitments the next most frequent categories, at 16.6 percent and 8.3 percent respectively. The most frequent admitting diagnosis of this sample was alcoholism, 75 percent, with the remaining 25 percent equally divided 
among schizophrenia, neurosis, and non-psychotic organic brain syndrome.

With such a small sample $(n=12)$, statistical significance of mean score differences is difficult to substantiate. The usual statistical comparison of the measure of variability involves the utilization of the students' "t" test for samples with independent means. For the admissions and releasees, paired observations mandated an analys is of variability for a sample with dependent means. The paired " $t$ " was utilized for this analysis, computing the significance of the mean of the difference between the two samples. of the eleven measures, three demonstrated significant differences in the direction of more favorable outcome for the releasees: Productivity I, significant at the .01 level; Psychological Distress, significant at the .005 level; and Legal Difficulties, significant at the .05 level. 
TABLE VII

PAIRED " $t$ " ON MATCHED OBSERVATIONS

\begin{tabular}{|c|c|c|c|c|c|}
\hline Scale & $\begin{array}{l}\text { Mean of the } \\
\text { Differences }\end{array}$ & $\begin{array}{c}\text { SD of the } \\
\text { Differences }\end{array}$ & df & $\begin{array}{l}\text { Paired } \\
\text { "t" }\end{array}$ & Significance \\
\hline Productivity I & 1.73 & 2.05 & 10 & 2.79 & $\mathrm{p}<.01$ \\
\hline $\begin{array}{l}\text { Interpersonal } \\
\text { Isolation--Family }\end{array}$ & .17 & 2.59 & 11 & .22 & n.s. \\
\hline $\begin{array}{l}\text { Interpersoral } \\
\text { Isolation--Friends }\end{array}$ & .50 & 2.02 & 11 & .86 & n.s. \\
\hline $\begin{array}{l}\text { Interpersonal } \\
\quad \text { Aggression--Friends }\end{array}$ & .08 & .79 & 11 & .36 & $\mathbf{n . 8 .}$ \\
\hline Psychological Distress & 4.25 & 4.56 & 11 & 3.23 & $\mathrm{p}<.005$ \\
\hline Systems Dependency & .75 & 5.14 & 11 & .50 & n.s. \\
\hline Legal Difficulties & .50 & .90 & 11 & 1.91 & $\mathrm{p}<.05$ \\
\hline Alcohol Abuse & .67 & 3.49 & 11 & .66 & n.s. \\
\hline Drug Abuse & -2.20 & 6.71 & 9 & -1.03 & n.s. \\
\hline Soft Drug Use & .33 & .78 & 11 & 1.48 & n.s. \\
\hline Productivity II & -.60 & 2.72 & 9 & -.69 & n.s. \\
\hline
\end{tabular}


Translating the mean raw scores into standardized scores more graphically illustrates the findings. The inpatient admission and releasee matched pairs' standardized scores are presented in Figure 2 .

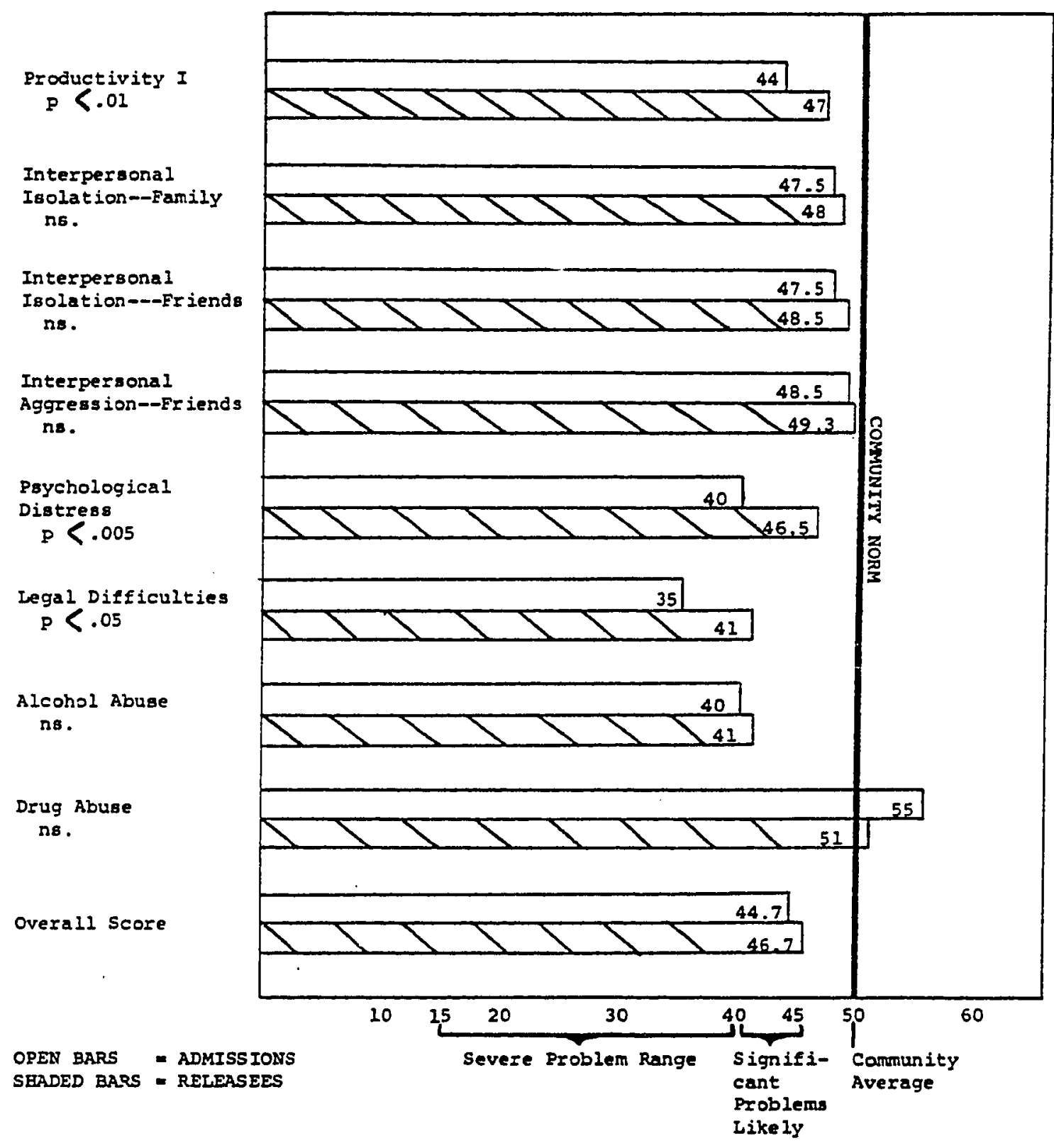

Eicure 2. Matched pairs: average MOM standard scores (Oregan 1975) 
From the demographic characteristics, admission type, and admitting diagnosis, one would expect the overall emergent problem area to be alcoholism. This is substantiated by the lower scores on the Alcohol Abuse scale. It was not expected that the Substance Abuse measures, Alcohol and Drug, would differ in any significant way from time one to time two for both the admission and releasee samples, since the time frame was identical for both groups. For an inpatient population, the literature predicts the most valid measure is Psychological Distress. The data appears to substantiate this prediction. Three of the eight standardized scales are approaching the severe problem range, two standard deviations below the community norm, with the lowest scale being Legal Difficulties. The remaining five scales, although they do not indicate significant differences in the admission and releasee scores, do exhibit a difference in the direction of more favorable outcome with the exception of the Drug Abuse scale. From these results, one would conclude with the developers of the instrument that it exhibits treatment sensitivity.

We may conclude from the data that service recipients do get better between admission and release. The lasting effects of this improvement remain to be tested in follow-up studies of the Subjects after they have remained in the community for a period of time. 